\title{
A CELL-BASED MOLECULAR TRANSPORT SIMULATOR FOR PHARMACOKINETIC PREDICTION AND CHEMINFORMATIC EXPLORATION
}

\author{
Xinyuan Zhang ${ }^{1}$, Kerby Shedden ${ }^{\dagger, 2}$, and Gus R. Rosania ${ }^{\dagger, 1,{ }^{*}}$ \\ ${ }^{1}$ Department of Pharmaceutical Science, University of Michigan College of Pharmacy, Ann Arbor, \\ MI 48109 \\ ${ }^{2}$ Department of Statistics, University of Michigan, Ann Arbor, MI 48109
}

\begin{abstract}
In the body, cell monolayers serve as permeability barriers, determining transport of drug molecules from one organ or tissue compartment to another. After oral administration, for example, drug transport across the epithelial cell monolayer lining the lumen of the intestine determines the fraction of drug in the gut that is absorbed by the body. By modeling passive transcellular transport properties in the presence of an apical to basolateral concentration gradient, we demonstrate how a computational, cell-based molecular transport simulator can be used to define a physicochemical property space occupied by molecules with desirable permeability and intracellular retention characteristics. Considering extracellular domains of cell surface receptors located on the opposite side of a cell monolayer as a drug's desired site-of-action, simulation of transcellular transport can be used to define the physicochemical properties of molecules with maximal transcellular permeability but minimal intracellular retention. Arguably, these molecules would possess very desirable features: least likely to exhibit non-specific toxicity, metabolism and side effects associated with high (undesirable) intracellular accumulation; and, most likely to exhibit favorable bioavailability and efficacy associated with maximal rates of transport across cells and minimal intracellular retention, resulting in (desirable) accumulation at the extracellular site-of-action. Calculated permeability predictions showed good correlations with PAMPA, Caco2, and intestinal permeability measurements, without "training" the model and without resorting to statistical regression techniques to "fit" the data. Therefore, cell-based molecular transport simulators could be useful in silico screening tools for chemical genomics and drug discovery.
\end{abstract}

\section{Keywords}

Metoprolol; permeability; chemical space; computer aided drug design; virtual screening; chemical genomics; cellular pharmacokinetics; cheminformatics; drug transport; PAMPA; Biopharmaceutics Classification System

\section{Introduction}

Drug uptake and transport across cell monolayers is an important determinant of in vivo bioavailability, biodistribution and activity. ${ }^{1}$ However, enzymes of low selectivity metabolize

CORRESPONDING AUTHOR: Gus R. Rosania, Ph.D., Department of Pharmaceutical Sciences, University of Michigan College of Pharmacy, 428 Church Street, Ann Arbor, MI 48109. Email: E-mail: grosania@ umich.edu. Phone: 734-763-1032. Fax: 734-615-6162.

${ }^{\dagger}$ Michigan Alliance for Cheminformatic Exploration 
drugs inside cells. ${ }^{2,} 3$ High permeability-high solubility drugs administered at high concentrations diffuse across cells fast enough -saturating transporters and enzymes- that only an insignificant fraction is diverted. ${ }^{4}, 5$ However, high intracellular drug concentrations can also be toxic. For example, unwanted accumulation of small molecules in mitochondria can interfere with mitochondrial function, inducing apoptosis. ${ }^{6,7}$ Similarly, unintentional accumulation of molecules in other organelles can induce phenotypic effects unrelated to a drug's primary mechanism of action - manifesting as non-specific toxicity. ${ }^{8}$ Nevertheless, many drugs are agonists or antagonists of cell surface receptors. ${ }^{9}$ Since receptor ligand binding domains are extracellular, intracellular drug accumulation is not essential for bioactivity. ${ }^{10}$ Thus, molecules designed to reach and accumulate at a desired extracellular site-of-action can combine high transcellular permeability with minimal intracellular accumulation. These desirable biopharmaceutical properties can lead -in turn- to potent, bioavailable, stable and non-toxic drug candidates.

Poor pharmacokinetics and toxicity are important causes of failure in the later, clinical stages of drug development ${ }^{4}, 11,12$. Therefore, ADMET (absorption, distribution metabolism, elimination, and toxicity) profiling is desirable as early as possible, before drug candidates are tested in patients. High throughput in silico ADMET models are one way to predict favored pharmacokinetics and toxicity profiles, early in the design of new drugs ${ }^{12}$. Mapping chemical spaces occupied by molecules possessing a desirable therapeutic activity and favored ADMET properties can be used to guide the design, synthesis and selection of series of lead compounds ${ }^{13-15}$. Along these lines, we sought to develop a fast, flexible and scalable computational tool for predicting epithelial transcellular passive permeability and intracellular accumulation, which are important determinants of oral absorption prediction, and toxicity prediction respectively $16-18$.

Drug solubility and intestinal permeability are the two key criteria for the FDA's Biopharmaceutics Classification System (BCS) ${ }^{19}$. At early stage of drug development mathematical models built based on data derived from in vitro experiments such as PAMPA (Parallel Artificial Membrane Permeation Assay) and Caco2 assay are widely used to predict human intestinal permeability. Most existing mathematical models to predict intestinal permeability are based on statistical regression methods that correlate PAMPA, Caco2, rat or human intestinal permeability measurements to $2 \mathrm{D}$ and/or 3D molecular descriptors ${ }^{20-22}$. However, the predictive power of these statistical models is inherently dependent on the quality of training data set, as well as the variability and reproducibility of the experimental assay. Furthermore, because of the statistical nature of the regression relationship, large amounts of data are needed to generate good models covering large realms of chemical space. To complement statistical regression methods, we decided to pursue a mechanism-based, mathematical modeling strategy to predict intestinal transcellular passive permeability, while also predicting the intracellular concentration of drug and its accumulation in organelles. In addition, based on permeability and intracellular concentration of a reference 'lead' compound, we also sought a non-statistical method that could map cell-permeant / impermeant and celltoxic / nontoxic chemical spaces relative to that compound, to guide the lead development efforts of pharmaceutical scientists and medicinal chemists.

Here, we present a mechanism-based modeling strategy that can predict intestinal transcellular passive permeability, as well as total drug accumulation in cells. Mathematically, the model describes transcellular transport of small molecules based on a physical, compartmental model of a cell, coupling sets of differential equations describing the physics of passive diffusion of small molecules across membranes ${ }^{23}$. Without incorporating enzymatic mechanisms or specific binding interactions, the current version of the model can predict the behavior of nonzwitterionic, monocharged small molecules possessing one ionizable functional group in the physiological $\mathrm{pH}$ range. Nevertheless, the behavior of more complex molecules and 
mechanisms -such as carrier mediate transport, metabolic processes or multiple ionizable groups- can be incorporated one-by-one in subsequent versions of the model, to predict the transport of low permeability, natural product-like molecules, and to mimic more complex, physiological conditions.

\section{Methods}

Starting with a cell-based, molecular mass transport model developed to study the accumulation of lipophilic cations in tumor cells ${ }^{23}$, we adapted the Nernst-Planck and Fick equations to simulate transport of molecules across epithelial cell monolayers, in the presence of an apical-to-basolateral, transcellular concentration gradient. For weakly-basic / acid, druglike small molecule, the cellular pharmacokinetic model considers three physicochemical properties as the most important determinants of intracellular accumulation and transport: 1) the logarithm of the lipid/water partition coefficient of the neutral form of the molecule, $\log \mathrm{P}_{\mathrm{n}}$;2) the logarithm of the lipid/water partition coefficient of the ionized form of the molecule, $\log \mathrm{P}_{\mathrm{d}}$; and, 3) the negative logarithm of the dissociation constant of the protonated functional group, $\mathrm{pK}_{\mathrm{a}}$. Drug concentrations in different intracellular compartments are coupled to each other according to the topological organization of the cell (Figure 1A, B). Different organelles have different $\mathrm{pHs}$ and transmembrane electrical potentials, so a molecule's charge in different organelles can vary according to the molecule's $\mathrm{pK}_{\mathrm{a}}$; and, transport properties across the membranes delimiting different compartments can vary depending on the membranes' electrical potential ${ }^{24-27}$. With the model developed herein, the concentration of molecules in different subcellular compartments and the transcellular permeability coefficient $\left(\mathrm{P}_{\mathrm{eff}}\right)$ can be calculated for different time intervals after cells are exposed to drug (see Supporting Information).

For modeling drug accumulation in the cytosolic compartment, the mitochondrial compartment, and the basolateral compartment the total mass change of the molecule with time can be expressed by Eq 1 to Eq 3:

$$
\frac{d m_{c}}{d t}=A_{a} J_{a, c}-A_{m} J_{c, m}-A_{b} J_{c, b},
$$

$$
\begin{gathered}
\frac{d m_{m}}{d t}=A_{m} J_{c, m}, \\
\frac{d m_{b}}{d t}=A_{b} J_{c, b},
\end{gathered}
$$

where $J$ is the net flux from the 'positive' side to the 'negative' side, $m$ is the total molecular mass, $t$ is time, $A$ is membrane surface area, subscripts $c, a, b$, and $m$ indicate cytosolic, apical, basolateral, and mitochondrial respectively. The direction from apical to basolateral compartment was defined from the 'positive' side to the 'negative' side.

To solve the above equations, the relationships between fluxes and masses must be specified. The bridge between these quantities is the concentration in each compartment. Each side of Eq 1, Eq 2 and Eq 3 is divided by the volumes of each compartment to get Eq 4, Eq 5, and Eq 6. 


$$
\begin{gathered}
\frac{d C_{c}}{d t}=\frac{A_{a}}{V_{c}} J_{a, c}-\frac{A_{m}}{V_{c}} J_{c, m}-\frac{A_{b}}{V_{c}} J_{c, b}, \\
\frac{d C_{m}}{d t}=\frac{A_{m}}{V_{m}} J_{c, m}, \\
\frac{d C_{b}}{d t}=\frac{A_{b}}{V_{b}} J_{c, b},
\end{gathered}
$$

where $C_{c}, C_{m}$, and $C_{b}$ are cytosolic, mitochondrial, and basolateral concentration, $V_{m}$, and $V_{b}$ are volumes of cytosolic, mitochondrial, and basolateral compartments respectively. The passive diffusion flux of neutral molecules across membranes is described by Fick's First Law:

$$
J=P\left(a_{o}-a_{i}\right)
$$

where $J$ is the molecular flux from the out side to the inside (i) ('negative' side) of the membrane, $P$ is the permeability of the molecules across cellular membranes, and $a$ is the activity of the molecules. For electrolytes the driving forces across cellular membrane are not only chemical potential but also electrical potential, which is described by the Nernst-Planck equation. With the assumption of a linear potential gradient across the membrane, a net current flow of zero and with each ion flux is at steady state, an analytical solution for the flux of the ion is

$$
J=P \frac{N}{e^{N}-1}\left(a_{o}-a_{i} e^{N}\right),
$$

where $N=z E F / R T, z$ is the electric charge, $F$ is the Faraday constant, $E$ is the membrane potential, $R$ is the universal gas constant, and $T$ is the absolute temperature. ${ }^{23}$ If $\mathrm{Eq} 7$ and $\mathrm{Eq}$ 8 are combined, the net fluxes across each membrane for both neutral forms and ionic forms can be described by Eq 9.

$$
J=P_{n}\left(a_{o, n}-a_{i, n}\right)+P_{d} \frac{N}{e^{N}-1}\left(a_{o, d}-a_{i, d} e^{N}\right),
$$

where $P_{n}$ is the permeability of neutral form across the membrane, $P_{d}$ is the permeability of the ionized form across the membrane, $a_{o, n}$ and $a_{i, n}$ are the activities of the neutral form outside and inside respectively, $a_{o, d}$ and $a_{i, d}$ are the activities of the ionized form outside and inside respectively. So the net fluxes across each membrane are:

$$
J_{a, c}=P_{n}\left(a_{n, a}-a_{n, c}\right)+P_{d} \frac{N_{a}}{e^{N_{a}}-1}\left(a_{d, a}-a_{d, c} e^{N_{a}}\right),
$$




$$
\begin{gathered}
J_{c, m}=P_{n}\left(a_{n, c}-a_{n, m}\right)+P_{d} \frac{N_{m}}{e^{N_{m}}-1}\left(a_{d, c}-a_{d, m} e^{N_{m}}\right), \\
J_{c, b}=P_{n}\left(a_{n, c}-a_{n, b}\right)+P_{d} \frac{N_{b}}{e^{N_{b}}-1}\left(a_{d, c}-a_{d, b} e^{N_{b}}\right),
\end{gathered}
$$

where $J_{a, c}, J_{c, m}$, and $J_{c, b}$ are net flux across apical membrane, mitochondrial membrane, and basolateral membrane respectively; $a_{a, n}, a_{c, n}, a_{m, n}$, and $a_{b, n}$ are the neutral molecular form activities in the apical compartment, cytosolic compartment, mitochondrial compartment and basolateral compartment respectively; $a_{a, d}, a_{c, d}, a_{m, d}$, and $a_{b, d}$ are the ionized molecular form activities in the apical compartment, cytosolic compartment, mitochondrial compartment and basolateral compartment, respectively; $N_{a}, N_{m}$, and $N_{b}$ are the $N$ values for apical membrane, mitochondrial membrane and basolateral membrane respectively. The Henderson-Hasselbalch equation (Eq 13) describes the activity ratio of neutral form molecules and ionized form molecules.

$$
\log \frac{a_{d}}{a_{n}}=i\left(p H-p K_{a}\right)
$$

where $a_{d}$ and $a_{n}$ are the ionized molecular form and the neutral molecular form respectively, $i$ is 1 for acids and -1 for bases; $p K_{a}$ is the negative logarithm of the dissociation constant. Therefore

$$
a_{d}=a_{n} \times 10^{i\left(p H-p K_{a}\right)},
$$

The relationship of the activities $\left(a_{n}\right.$ and $\left.a_{d}\right)$ and the total molecular concentration can be expressed by Eq 15 and Eq 16, ${ }^{28}$

$f_{n}=a_{n} / C_{t}=\frac{1}{W / \gamma_{n}+K_{n} / \gamma_{n}+W \times 10^{i\left(p H-p K_{a}\right)} / \gamma_{d}+K_{d} \times 10^{i\left(p H-p K_{a}\right)} / \gamma_{d}}$,

$$
f_{d}=a_{d} / C_{t}=f_{n} 10^{i(p H-p K a)},
$$

$W$ is the volumetric water fraction, $\gamma$ the activity coefficient, and $K_{n}$ and $K_{d}$ the sorption coefficients of the neutral and the ionized molecules respectively. $K_{n}$ and $K_{d}$ are estimated by Eq 17, where $L$ is the lipid fraction in each compartment, and $K_{o w}$ the lipophilicity. In this model liposome partition coefficients are used as $K_{\text {ow }}$.

$$
K_{n / d}=L \times 1.22 \times K_{o w, n / d},
$$

The activity coefficient of all neutral molecules $\left(\gamma_{n}\right)$ is related to the ionic strength $I$ (moles). Using the Setchenov equation, at $I=0.3 \mathrm{~mol}, \gamma_{n}$ is 1.23 . The activity of ions $\left(\gamma_{d}\right)$ is calculated with the Davies approximation of the modified Debye-Hückel equation. ${ }^{23}$ For monovalent ions at $I=0.3 \mathrm{~mol}, \gamma_{d}$ is 0.74 . For conditions outside the cell, no corrections for the ionic 
strength are made, and activities are set approximately equal to concentration $(\gamma=1) .{ }^{23} \mathrm{Plug}$ Eq 15 and Eq 16 into Eq 10, Eq 11 and Eq 12 to get Eq 18, Eq 19 and Eq 20.

$$
\begin{gathered}
J_{a, c}=P_{n}\left(f_{n, a} C_{a}-f_{n, c} C_{c}\right)+P_{d} \frac{N_{a}}{e^{N_{a}}-1}\left(f_{d, a} C_{a}-f_{d, c} C_{c} e^{N_{a}}\right), \\
J_{c, m}=P_{n}\left(f_{n, c} C_{c}-f_{n, m} C_{m}\right)+P_{d} \frac{N_{m}}{e^{N_{m}}-1}\left(f_{d, c} C_{c}-f_{d, m} C_{m} e^{N_{m}}\right), \\
J_{c, b}=P_{n}\left(f_{n, c} C_{c}-f_{n, b} C_{b}\right)+P_{d} \frac{N_{b}}{e^{N_{b}}-1}\left(f_{d, c} C_{c}-f_{d, b} C_{b} e^{N_{b}}\right),
\end{gathered}
$$

Plugging Eq 18, Eq 19 and Eq 20 into Eq 4, Eq 5, and Eq 6 to get Eq 21, Eq 22, and Eq 23.

$$
\begin{gathered}
\frac{d C_{c}}{d t}=\frac{A_{a}}{V_{c}}\left[P_{n}\left(f_{n, a} C_{a}-f_{n, c} C_{c}\right)+P_{d} \frac{N_{a}}{e^{N_{a}}-1}\left(f_{d, a} C_{a}-f_{d, c} C_{c} e^{N_{a}}\right)\right] \\
-\frac{A_{c}}{V_{c}}\left[P_{n}\left(f_{n, c} C_{c}-f_{n, m} C_{m}\right)+P_{d} \frac{N_{m}}{e^{N_{m}-1}}\left(f_{d, c} C_{c}-f_{d, m} C_{m} e^{N_{m}}\right)\right], \\
-\frac{A_{b}}{V_{c}}\left[P_{n}\left(f_{n, c} C_{c}-f_{n, b} C_{b}\right)+P_{d} \frac{N_{b}}{e^{N_{b}}-1}\left(f_{d, c} C_{c}-f_{d, b} C_{b} e^{N_{b}}\right)\right] \\
\frac{d C_{m}}{d t}=\frac{A_{m}}{V_{m}}\left[P_{n}\left(f_{n, c} C_{c}-f_{n, m} C_{m}\right)+P_{d} \frac{N_{m}}{e^{N_{m}}-1}\left(f_{d, c} C_{c}-f_{d, m} C_{m} e^{N_{m}}\right)\right], \\
\frac{d C_{b}}{d t}=\frac{A_{b}}{V_{b}}\left[P_{n}\left(f_{n, c} C_{c}-f_{n, b} C_{b}\right)+P_{d} \frac{N_{b}}{e^{N_{b}}-1}\left(f_{d, c} C_{c}-f_{d, b} C_{b} e^{N_{b}}\right)\right],
\end{gathered}
$$

The membrane permeability $P^{23}$ can be estimated using:

$$
P=D K / \triangle x,
$$

$D$ is the diffusion coefficient which is about $10^{-14} \mathrm{~m}^{2} / \mathrm{s}$ for organic molecules in biomembranes. $K$ is the partition coefficient, and approximates $K_{o w} . \Delta x$ is the membrane thickness, and is considered about $50 \mathrm{~nm}$ for biomembranes. Plugging these estimated numbers into Eq 24 and doing a logarithm conversion, gives Eq 25.

$$
\log P=\log K_{o w}-6.7,
$$

Per definition, the transcelular permeability coefficient $\left(P_{\text {eff }}\right)$ is calculated using:

$$
P_{e f f}=\frac{d C_{b} \times V_{b}}{d t \times A_{a a} \times C_{a}}
$$


where $A_{a a}$ is the cellular monolayer area, $d C_{b}$ the total concentration change in basolateral compartment with time $d t, C_{a}$ the concentration in apical compartment which is assumed to be constant in this model.

MATLAB $^{\circledR}$ was used to solve the differential equation system (Eq 21, Eq 22, and Eq 23). The concentrations in cytosol $\left(C_{c}\right)$, mitochondria $\left(C_{m}\right)$, basolateral compartment $\left(C_{b}\right)$, and transcellular permeability coefficient $\left(P_{\text {eff }}\right)$ were solved numerically. Cellular parameters describing the intestinal epithelial cell were obtained from the literature. The MATLAB ${ }^{\circledR}$ solver and graphics scripts are included as Supporting Information.

Using this model, permeability and intracellular concentration of 36 compounds were calculated (Figure 2,3). These compounds were selected based on the following criteria: 1 ) they are mono-ionized or neutral in the physiological $\mathrm{pH}$ environment; 2) their $\log \mathrm{P}_{\mathrm{n}}, \mathrm{pK}_{\mathrm{a}}$, and $\mathrm{Caco} 2$ permeability were experimentally measured and published; 3 ) their $\mathrm{Caco} 2$ permeabilities were experimentally measured and published. The literature sources, $\log \mathrm{P}_{\mathrm{n}}$, $\log \mathrm{P}_{\mathrm{d}}, \mathrm{pKa}$, chemical structures and calculated permeability and intracellular concentration obtained with our model are included as Supporting Information.

The octanol / water partition coefficients $\left(\log \mathrm{P}_{\mathrm{n}}(\mathrm{o} / \mathrm{w})\right)$ were experimental data obtained from SRC PhysProp Database and other references in the scientific literature $29-31$, and $\mathrm{pK}_{\mathrm{a}}$ values were also experimental data obtained from several published articles $10,32-40$. The partition coefficients of the ionized state of the molecules $\left(\log \mathrm{P}_{\mathrm{d}}\right)$ were estimated from $\log \mathrm{P}_{\mathrm{n}}$ according to Eqn $27: 23$

$$
\log P_{d}=\log P_{n}-3.7
$$

Eqns 28-32 were used to obtain the liposomal partition coefficient for both neutral forms and ionic forms of bases and acids. ${ }^{34}$ For ampholytes to get the liposomal partitioning the equation for neutral forms of bases was applied.

(For neutral forms of bases) $\log P_{n, l i p}=0.33 \log P_{n, o c t}+2.2, R^{2}=0.69$,

(For cationic forms of bases) $\log P_{d, l i p}=0.37 \log P_{d, o c t}+2, R^{2}=0.49$,

(For neutral forms of acids) $\log P_{n, l i p}=0.37 \log P_{n, o c t}+2.2, R^{2}=0.89$,

(For anionic forms of acids) $\log P_{d, l i p}=0.33 \log P_{d, o c t}+2.6, R^{2}=0.72$,

To investigate the prediction power for intestinal permeability of this model, permeabilities of drugs with diverse structures spanning a range of $\log \mathrm{P}_{\mathrm{n}}$ and $\mathrm{pK}_{\mathrm{a}}$ values were calculated. As described above, $\log \mathrm{P}_{\mathrm{n}}(\mathrm{o} / \mathrm{w})$ obtained from literatures were converted to $\operatorname{lipsomal} \log \mathrm{P}_{\mathrm{n}, \mathrm{lip}}$ and $\log \mathrm{P}_{\mathrm{d} \text {,lip }}$ using Eqn 27-Eqn 31 and used in calculation. Linear regression was used to compare predicted permeability values with the Caco-2, PAMPA, and human intestinal permeability adopted from literatures $1,12,40-47$. As noticed, Caco-2 permeability data obtained from different references differ even for the same drug, thus the mean values of Caco- 2 
permeability obtained from different literature sources were used to compare with the predicted permeability.

Cell-permeant nontoxic chemical space, cell-permeant toxic chemical space, cell-impermeant chemical space, cell-permeant chemical space, cell-toxic chemical space, and cell-nontoxic chemical space were defined by calculating $P_{e f f}, C_{c}$, and $C_{m}$ of weakly basic monocationic molecules spanning $p K_{a}$ from 1 to $14, \log P_{n}$ from -5 to +5 , and $\log P_{d}$ from -5 to +5 . Each one of these physicochemical parameters was varied independently in 0.1 unit intervals, and combined with the other parameters. To evaluate the robustness of the results obtained with the model, chemical space plots were visually inspected for reproducibility and consistency after changing one parameter at a time while keeping the others unchanged (Supporting Information). The change of $\log \mathrm{P}_{\mathrm{n}}$ and $\log \mathrm{P}_{\mathrm{d}}$ were discussed under two conditions: (1). $\log \mathrm{P}_{\mathrm{n}}$ and $\log \mathrm{P}_{\mathrm{d}}$ changed independently; and (2). $\log \mathrm{P}_{\mathrm{n}}$ and $\log \mathrm{P}_{\mathrm{d}}$ were associated by Eqn 27 to Eqn 31. Parameter values used in calculation as well as graphing scripts are included in the Supporting Information. Addtional methods and results -testing the model for self-consistency and robustness- are described in the Supporting Information.

\section{Results}

\section{A cellular pharmacokinetic model of passive transcellular drug transport}

Transcellular permeability is a key property determining biodistribution of soluble drug molecules from one body compartment to another. For an orally administered drug with high solubility, the transcellular permeability of the cells lining the intestine determines the fraction of drug in the intestine that is absorbed by the body. For a monolayer of cells of area $A$, the

transcellular permeability is defined: $P=\frac{d C \cdot V}{d t \cdot A \cdot C_{0}}(\mathrm{~m} / \mathrm{sec})$, where $d C / d t$ is the flux across the monolayer, $V$ the volume in the receiver chamber, $A$ the surface area of the monolayer, and $C_{0}$ the initial concentration in the donor compartment.

In epithelial cells lining the lumen of the intestine (Fig. 1A), apical microvilli make the apical surface area ${ }^{48}$ much greater than the basolateral surface area. ${ }^{9}$ The length of an epithelial cell is approximately 10 to $15 \mu \mathrm{m}$. $A_{a a}$ is the effective cross-sectional area of each cell, corresponding to the total area of the cell monolayer across which transport occurs, divided by the total number of cells involved in the transcellular transport process. Finally, the total volume of the cell $V$ constrains its overall geometry in relation to $A_{a}, A_{b}$ and $A_{a a}$. Based on these parameters, the permeability of an intestinal epithelial cell can be expressed as:

$P_{e f f}=\frac{d C_{b} \times V_{b}}{d t \times A_{a a} \times C_{a}}$, where $V_{\mathrm{b}}$ is the volume of the basolateral compartment, $d C_{b} / d t$ is the rate of change in concentration of drug in the basolateral compartment, and $\boldsymbol{C}_{\mathrm{a}}$ is the concentration of drug in the apical compartment (under conditions in which the concentration of drug in the basolateral compartment is small $\left(\boldsymbol{C}_{\boldsymbol{b}} \sim 0\right)$ and the concentration in the apical compartment $\boldsymbol{C}_{\boldsymbol{a}}$ is held constant).

Setting cellular parameters to mimic an intestinal epithelial cell, the model captures the mass transport process followed by a weak base or acid (non-zwitterionic molecule), through said cell (Fig. 1B). Such molecules exist as equilibrium mixtures of neutral and ionic states, their proportions determined by the $\mathrm{pH}$ of the immediate environment. In the case of high solubilityhigh permeability molecules, passive diffusion is the dominant transcellular transport mechanism $4,5,46,49$, driven by concentration gradients of drugs and ions, and the transmembrane electrical potential. Assuming that mixing of molecules within each intracellular compartment is faster than the rate at which they traverse the delimiting membranes, the mass of drug in each compartment can be modeled using a set of coupled differential equations based on an empirical relationship between lipophilicity and 
transmembrane permeability of small molecules, and Fick's Law of diffusion ${ }^{23}$. To traverse the cell, molecules first cross the apical membrane, distributing homogenously in the cytosol and partitioning into cytoplasmic lipids. From the cytosol, they also partition into and out of organelles, and exit the cell across the basolateral membrane.

After simulating the transcellular transport process, the calculated permeability values were found to be consistent with the experimental values. Specifically, we first considered the intracellular concentration and permeability coefficient of molecules with physicochemical properties resembling a beta adrenergic receptor blocking drug - metoprolol (Figure 2). Metoprolol is orally bioavailable, but less permeable and less toxic than more hydrophobic relatives, such as propranolol. ${ }^{50}$ Comparing the calculated results (Table 1) with the experimental data (Table 2), the calculated permeability coefficient of metoprolol is similar to the human permeability coefficient measured in intestinal perfusion experiments, ${ }^{51}$ and the coefficient of propranolol is one order of magnitude larger than human permeability coefficients. ${ }^{51}$ The in silico permeabilities are two to three orders of magnitude larger than those measured with Caco2 assays, and closer to the actual human permeability coefficients. The discrepancy between the $\mathrm{Caco} 2$ and in silico permeability can be explained if the noncellular, transwell membrane resistance of the in vitro measurement -associated with the presence of a diffusive boundary layer at the membrane-liquid interface- is taken into account.

\section{Comparing the Calculated Permeabilities with Experimental Permeability Data}

Correlation of predicted permeability with Caco2 permeability and human intestinal permeability were plotted to evaluate the model. Figure 2 is the scatter plot of predicted permeability and Caco 2 permeability of seven $\beta$ - adrenergic receptor blockers -alprenolol, atenolol, metoprolol, oxprenolol, pindolol, practolol, and propranolol -possessing the same core structure (Table 1). This homologous set of drugs has similar $\mathrm{pK}_{\mathrm{a}}$ values (Table 1). A linear relationship was observed $\left(\log \left(P_{\text {eff, predicted }}\right)=0.44 \log \left(P_{\text {eff,Caco2 }}\right)-2.4\left(R^{2}=0.78\right)\right)$ between the logarithm values of predicted permeability $(\mathrm{cm} / \mathrm{sec})$ and the logarithm values of average measured $\mathrm{Caco} 2$ permeability $(\mathrm{cm} / \mathrm{sec})$. The significance $\mathrm{F}$ of this regression is $<0.011$ (confidence level is 95\%).

Next, we examined the correlation of predicted and Caco-2 permeability of 36 structurally unrelated compounds (including the 7 shown in Fig 2; Figure 3). By visual inspection, the predicted permeability of compounds shown in Fig. 3 can be readily categorized into two groups: high permeability and low permeability. Using the predicted permeability of Metoprolol (No. 18) as a reference (dashed horizontal line), compounds that fall into the dotted oval are predicted to be high permeability by the model and also exhibit high permeability in Caco2 assays. Most high permeability compounds transport predominantly by the transcellular pathway with some exceptions: for example, P-glycoprotein reportedly affects acebutolol (No. 1 in Fig. 3) intestinal absorption ${ }^{52}$. In the scatter plot, the predicted permeability of acebutolol was higher than the Caco2 permeability, which is consistent with P-glycoprotein efflux not being captured by the model. In contrast, many (predicted) low permeability drugs and molecules exhibit a significant paracellular or active transport pathway. For example, mannitol (No.17 in Fig. 3) is widely used as a passive paracellular permeability marker, so its measured permeability reflects paracellular transport not the passive transcellular diffusive transport being predicted by the model. Conversely, taurocholic acid and valproic acid are substrates of transporters ${ }^{41}$ increasing the apparent permeability above levels predicted by the model.

Next, the calculated permeability of compounds that fell into the dotted oval in Fig. 3 (those with correctly predicted, high Caco2 permeability) were compared with PAMPA assay results, as reported in the scientific literature (Table 2). For each individual PAMPA assay result, compounds with higher-than-metoprolol permeability were defined 'high permeability' and lower-than-metoprolol permeability were defined 'low permeability' $53-55$. Table 2 shows that 
PAMPA permeability measured in different conditions is different and is affected by buffer conditions ${ }^{54}$. According to FDA waiver guidance ${ }^{56}$ the reference drugs ketoprofen and naproxen would be misclassified in two PAMPA measurement, using metoprolol as a reference in published measurments (Table 2) -but they are correctly classified by our predictive, computational model.

To compare the predicted permeability with human intestinal permeability a scatter plot was graphed (Figure 4). Since human intestinal permeability data are scarce, among the 36 compounds used in this study (those with experimentally measured $\log \mathrm{P}, \mathrm{pKa}$, and monocharged in the physiological $\mathrm{pH}$ range) we only found ten of them having human intestinal permeability data. A simple linear relationship was obtained $\left(\log \left(P_{\text {eff,predicted }}\right)=0.95 \log \right.$ $\left.\left(P_{\text {eff,human }}\right)-0.58\left(R^{2}=0.72\right)\right)$ for log of predicted permeability and log of human intestinal permeability. The significance $F$ of multivariate regression is $<0.0018$ (confidence level is 95\%). The calculated permeability and human intestinal permeability were listed in Table 3.

\section{Probing the effect of drug physicochemical properties on cellular pharmacokinetics}

The physicochemical properties of drug molecules influence intracellular concentration and transcellular permeability. For a monovalent cationic weak base, the model explicitly considers how three different parameters (the logarithm of the lipid/water partition coefficient of the neutral form of the molecule, $\log \mathrm{P}_{\mathrm{n}}$; the logarithm of the lipid/water partition coefficient of the ionized form of the molecule, $\log \mathrm{P}_{\mathrm{d}}$; and the negative logarithm of the dissociation constant of the protonated functional group, $\mathrm{pK}_{\mathrm{a}}$ ) can affect these properties. In silico, one can change each property one at a time, keeping the others unchanged. Two conditions were considered here: (1). $\log P_{n}$ and $\log P_{d}$ changed independently (Fig. 5A); and (2). $\log P_{n}$ and $\log P_{d}$ were associated by Eqn 27 to Eqn 31 (Fig. $5 B$ ). Although the actual relationship between $\log \mathrm{P}_{\mathrm{n}}$ and $\log \mathrm{P}_{\mathrm{d}}$ of a molecule is neither perfectly linear nor completely independent, simulating different relationships between $\log \mathrm{P}_{\mathrm{n}}$ and $\log \mathrm{P}_{\mathrm{d}}$ is one way to assess how physicochemical properties affect calculated permeability and intracellular concentration. For a metoprolol-like molecule $\left(\mathrm{pK}_{\mathrm{ab}}=9.7 ; \log \mathrm{P}_{\mathrm{n}}(\mathrm{o} / \mathrm{w})=1.88 ; \log \mathrm{P}_{\mathrm{d}}=\log \mathrm{P}_{\mathrm{n}}(\mathrm{o} / \mathrm{w})-3.7\right)$ cytosolic concentrations remain low and constant as $\log \mathrm{P}_{\mathrm{n}}$ is varied between -5 to +3 (Fig. 5A-left and Fig. 5B-left). However, increasing $\log \mathrm{P}_{\mathrm{n}}$ from +3 to +5 increases cytosolic concentration to levels that greatly exceed the extracellular drug concentration. For mitochondrial concentrations, as $\log \mathrm{P}_{\mathrm{n}}$ increases from -5 to 5 , there is a pronounced decrease in mitochondrial sequestration. For the transcellular permeability, there is an increase in permeability between $\log \mathrm{P}_{\mathrm{n}}=3$ to $\log \mathrm{P}_{\mathrm{n}}=5$, in parallel to the increase in cytosolic concentration. Thus, for a metoprolol-like molecule, the desired $\log \mathrm{P}_{\mathrm{n}}$ lies between 2 and 3 , at which cytosolic and mitochondrial concentrations are minimal, whereas transcellular permeability is maximal.

Just as for the $\log \mathrm{P}_{\mathrm{n}}$ parameter, the $\log \mathrm{P}_{\mathrm{d}}$ values of a metoprolol-like molecule were varied to determine the effect on intracellular concentrations and permeability coefficients. For $\log \mathrm{P}_{\mathrm{d}}$ values less than 2 , the intracellular concentration of drug at the steady state is low and constant (Fig. 5A-middle and Fig. 5B-middle). However if $\log \mathrm{P}_{\mathrm{d}}$ increases above 2, cytosolic concentrations increase and greatly exceed extracellular drug concentration. For $\log \mathrm{P}_{\mathrm{d}}$ values greater than 3 , there is more than a 10 -fold increase in mitochondrial concentration above the extracellular concentration. Nevertheless, increasing $\log \mathrm{P}_{\mathrm{d}}$ has the greatest influence on the transcellular permeability value, with increasing $\log \mathrm{P}_{\mathrm{d}}$ associated with the fastest rates of transcellular transport. Thus, according to these simulations, increasing $\log \mathrm{P}_{\mathrm{d}}$ leads to the very desirable effects of increasing transcellular transport rates, although it also leads to the very undesirable effect of increasing cytosolic and mitochondrial drug accumulation.

Finally, the $\mathrm{pK}_{\mathrm{a}}$ value of a metoprolol-like molecule was varied, to study the effect on subcellular transport and biodistribution properties. Compared to the other two parameters, increasing $\mathrm{pK}_{\mathrm{a}}$ from 9 to 14 has little effect on transmembrane permeability (Fig. 5A-right and 
Fig. 5B-right). However, decreasing it from 9 to 7 nearly quadrupled the permeability. Lowering the $\mathrm{pK}_{\mathrm{a}}$ below 9 increased the cytosolic concentration, while increasing it above 9 increased the mitochondrial concenctration. Thus the $\mathrm{pK}_{\mathrm{a}}$ of metoprolol is near the point where cytosolic and mitochondrial concentrations are minimized while transcellular permeability is maximized. Again, by varying the physicochemical properties of a metoprolol-like molecule one at a time, the model suggests that the cellular pharmacokinetic properties of metoprolol are quite good and would be difficult to improve based on diffusive transport properties, by varying one physicochemical property of the molecule at a time.

\section{Chemical space definitions and solutions}

Molecules with intracellular concentrations less than -and permeability values greater thanthose for a molecule with metoprolol-like physicochemical properties would posses desirable pharmaceutical features, as these characteristics would be expected to lead to even higher oral bioavailability, improved biodistribution, and decreased metabolism, relative to metoprolol. To identify the physicochemical properties associated with such molecules, we proceeded to calculate the intracellular concentrations and transcellular permeability values of over a million different possible combinations of $\mathrm{pK}_{\mathrm{a}}, \log \mathrm{P}_{\mathrm{n}}$ and $\log \mathrm{P}_{\mathrm{d}}$ values. Four different regions of chemical space were defined relative to the steady state permeability and intracellular concentration of a molecule with metoprolol-like properties, as follows: 1) Permeant: Molecules with calculated $\mathrm{P}_{\text {eff }}$ equal or larger than $\mathrm{P}_{\text {eff }}$ of the reference; 2) Impermeant: Molecules with calculated $\mathrm{P}_{\text {eff }}$ less than the reference $\mathrm{P}_{\text {eff }}$; 3 ) NonToxic: Molecules with both $\mathrm{C}_{\text {cyto }}$ and $\mathrm{C}_{\text {mito }}$ equal or less than $\mathrm{C}_{\text {cyto }}$ and $\mathrm{C}_{\text {mito }}$ of the reference molecule; 4) Toxic: Molecules with either $\mathrm{C}_{\text {cyto }}$ or $\mathrm{C}_{\text {mito }}$ larger than $\mathrm{C}_{\text {cyto }}$ or $\mathrm{C}_{\text {mito }}$ of the reference molecule. Again, two indepent set of simulations were carried out, based on perfectly correlated and uncorrelated $\log \mathrm{P}_{\mathrm{n}}$ and $\log \mathrm{P}_{\mathrm{d}}$ values.

Complete analysis of regions of physicochemical property space surrounding molecules with metoprolol-like properties (Figure 6 and Supporting Information) reveal the extent to which cell permeability and toxicity are related for this particular set of compounds. First, we consider the simulations in which $\log \mathrm{P}_{\mathrm{n}}$ and $\log \mathrm{P}_{\mathrm{d}}$ are varied independently from each other. Note that about $42.7 \%$ of total chemical space is occupied by combinations of $\mathrm{pK}_{\mathrm{a}}, \log \mathrm{P}_{\mathrm{n}}$ and $\log \mathrm{P}_{\mathrm{d}}$ that would make molecules more permeant than a molecule with metoprolol-like properties (Fig. $6 A$ ). The remaining $57.3 \%$ is occupied by combinations of $\mathrm{pK}_{\mathrm{a}}, \log \mathrm{P}_{\mathrm{n}}$ and $\log \mathrm{P}_{\mathrm{d}}$ that would make molecules less permeant than a molecule with metoprolol-like properties. Combinations of $\mathrm{pK}_{\mathrm{a}}, \log \mathrm{P}_{\mathrm{n}}$ and $\log \mathrm{P}_{\mathrm{d}}$ that lead to intracellular concentrations greater than those obtained with a molecule with metoprolol-like physicochemical properties lie within toxic chemical space, by definition. This region of chemical space comprises $60.6 \%$ of the total chemical space, with the remaining $39.4 \%$ falling in non-toxic space (Fig. 6B). If cellular permeability and toxicity were completely unrelated to each other, one would expect that $1.5 \%$ of the molecules would fall under permeant-nontoxic space $(16.8 \%$ permeant nontoxic $=39.4 \%$ nontoxic $\times 42.7 \%$ permeant). However, the actual fraction of molecules falling in cell permeant non-toxic space (Fig. $6 \mathrm{C}$ ) is $1.5 \%$, as permeability and intracellular accumulation are partly related to each other. Thus, while combinations of $\mathrm{pK}_{\mathrm{a}}, \log \mathrm{P}_{\mathrm{n}}$ and $\log \mathrm{P}_{\mathrm{d}}$ promoting permeability and nontoxicity work against each other to some degree, there is a small chunk of physicochemical property space where molecules with greater permeability than metoprolol, but reduced intracellular accumulation may reside. Indeed, there may be a small but significant number of molecules possessing a combination of physicochemical properties leading to improved bioavailability and biodistribution properties relative to a molecule with metoprolollike properties. Of noteworthy significance, the existence of a significant region of chemical space harboring molecules with desirable properties was not readily apparent when the individual physicochemical properties of the metoprolol-like reference molecule were varied one-at-a-time, as demonstrated in the previous section (Figure 5). 
Last, we mapped the chemical space surrounding a molecule with metoprolol-like physichochemical properties, under conditions in which $\log \mathrm{P}_{\mathrm{n}}$ and $\log \mathrm{P}_{\mathrm{d}}$ are perfectly coupled to each other in a linear relationship (Figure 7). Under these conditions, property space is reduced to a plane, with a molecule of metoprolol-like features sitting at the intersection of the permeant-impermeant and toxic-nontoxic space. The impermeant nontoxic and the impermeant toxic were of $47.6 \%$ and $7.5 \%$ total chemical space. Most importantly while permeant toxic occupies $43.7 \%$ of total chemical space respectively, permeant nontoxic occupies $0.11 \%$ of chemical space. Thus, our simulations indicate that the extent of $\log \mathrm{P}_{\mathrm{n}}$ and $\log \mathrm{P}_{\mathrm{d}}$ coupling most severely restricts the ability to optimize a molecule with metoprolol-like features. Furthermore, examining where permeant non-toxic space exists relative to metoprolol, one finds that lowering the pKa is the only way to both increase the permeability and decrease the intracellular accumulation (toxicity) of metoprolol. For the beta-blockers, the pKa of the molecule is determined by an isopropyl amine group that is shared by all the congeners (Table I), and therefore may not be changed. One way around this constraint would be to change the ionization properties of the molecules by making them zwitterionic at physiological $\mathrm{pH}$. However, the current model cannot capture the behavior of zwitterions, so a theoretical analysis of this optimization strategy must await development and validation of more advanced versions of the model.

\section{Discussion}

Transport of small molecules into and out of cells and organelles is determined by both passive and active transport mechanisms. The cellular pharmacokinetic model elaborated in this study specifically captures passive transport mechanisms, determined by the physicochemical properties of small molecules, their interactions with phospholipid bilayers, and the concentration gradients of ions and macromolecules across cellular membranes. $22,48,57$, 58 Empirical $^{12,22,59}$ and theoretical ${ }^{60-62}$ considerations establish three physicochemical properties of small molecules as key determinants of passive transport across membranes: size, charge, and lipophilicity. Most molecules used for drug discovery and chemical genomics investigations are "small", i.e. between 200 and 800 daltons, and therefore similar in size. Thus, the model is suitable for comparing the behavior of small molecules within this limited size range, where the main physicochemical properties influencing the distribution of molecules in cells are the multiple ionization states, and the concentration and lipophilicity of each ionic form.

For model validation, metoprolol was used as a reference because it is an FDA-approved drug that is $95 \%$ absorbed in the gastrointestinal tract $^{1}$, and it is recommended as an internal standard -to be included in experiments that assess drug permeability 56 - by the FDA. Metoprolol is generally included in published PAMPA, Caco2 and intestinal permeability datasets, as a reference point with which to establish the threshold between high and low permeability compounds. Several metoprolol relatives -like atenolol- are orally-bioavailable, moderateabsorption, low-metabolism, low-toxicity, renally-cleared $36,63-66$ with a well-characterized, passive-transport absorption mechanism, ${ }^{67}$ in vitro and in vivo permeability characteristics, 51,68 and measured micro $\mathrm{pK}_{\mathrm{a}} / \log \mathrm{P}$ properties ${ }^{34}$. Using the physicochemical properties of metropolol as a reference, cell-based molecular transport simulations were used to calculate the pharmaceutical properties of related beta adrenergic receptor antagonists. Setting cellular parameters and model geometry to mimic an intestinal epithelial cell, the simulations permitted testing the effects of different biological and chemical parameters on intracellular concentrations and transcellular permeability coefficients, through time. The steady state values for high permeability compounds were comparable to experimental measurements performed on cells lining the intestine, obtained through intestinal, in vivo perfusion experiments, and $\mathrm{Caco} 2$, in vitro permeability assays $22,69,70$. In addition, running over a million different combinations of $\log \mathrm{P}_{\mathrm{n}}, \log \mathrm{P}_{\mathrm{d}}$ and $\mathrm{pK}_{\mathrm{a}}$ through the simulation allowed us to 
define a phyiscochemical property space leading to the most desirable biopharmaceutical characteristic (higher transcellular permeability with lower intracellular accumulation), relative to the physicochemical properties of metoprolol.

We note that as a cheminformatic tool to analyze the biopharmaceutical properties of small molecule libraries, the $\log \mathrm{P}$ and $\mathrm{pKa}$ values may be calculated using other cheminformatic software packages, and then used as input in our simulator, to map the space that is occupied by molecules with different permeability and intracellular retention characteristics. Also, we note that since intracellular accumulation and permeability are related to each other, optimizing a single biopharmaceutical property (permeability) of a compound at a time may lead to unfavorable biodistribution properties (intracellular accumulation) associated with toxicity or drug clearance by metabolism. Indeed, complex properties like bioavailability may be predictable as non-linear functions of the fundamental physicochemical properties of molecules, under conditions in which transcellular transport is maximized and intracellular concentrations are minimized. Due to the limited experimental data available for fitting statistical models, and the relatively complex behaviors apparent in the simplified model presented in this study, our results suggest that a purely empirical, statistical regression models built from human, Caco2 or even PAMPA permeability data would be comparatively limited in their ability to predict bioavailability of small molecule drugs. Thus, cellular pharmacokinetic simulations could be used to complement to the more conventional, regression-based statistical approaches. This is especially true in situations when the statistical models lack power, such as when assay measurements are too variable or of low quality, or when a training dataset is unavailable, of dubious quality or too sparse. With continued validation and refinement, cell-based mass transport simulators can become increasingly sophisticated in their ability to capture more complex phenomena of pharmaceutical importance.

Admittedly the scope of the current, passive diffusion model is narrow, as its predictions apply only to non-zitterionic, monocharged molecules within a limited size range, administered at high concentrations so that they saturate specific binding sites on intracellular proteins, enzymes and transporters. However the therapeutic impact of the model could be substantial, since $80 \%$ of currently marketed therapeutic products are small molecules, administered orally and at high concentrations. ${ }^{19}$ Moreover the majority of these do target cell surface receptors or ion channels. ${ }^{9}$ The FDA's Biopharmaceutics Classification System 47 recognizes four classes of oral drug products: Class I (high solubility-high permeability); Class II (low solubility-high permeability); Class III (high solubility-low permeability); and class IV (low solubility-low permeability). The model is mostly relevant to Class I and II small molecule drugs, which turn out to be very common and well-behaved, encompassing about half of the drug products on the market. ${ }^{19}$ Since extracellular receptor binding allows maximizing a drug's transcellular permeability while minimizing intracellular accumulation, our model provides a mechanistic explanation as to why the major class of well-behaved, orallybioavailable drugs currently on the market does often target extracellular domains of cell surface receptors.

To conclude, cell-based molecular transport simulators can be used to make other predictions in addition to transcellular permeability, that can also be experimentally tested. Because each component that goes into the model can be studied and improved independently, more precise membrane transport equations including additional variables (such as molecular weight) 60 , 62 and additional subcellular compartments could be readily incorporated into the models albeit at the expense of greater computational complexity. Indeed, by checking predictions with experiments, the model can be gradually improved and evolved, and its scope can be extended to describe the transport of an increasing variety of molecules (such as zwitterions), under increasingly diverse conditions. Using single cells as pharmacokinetic units, it should 
be possible to model transport functions in multicellular organizations, simulating transport functions in tissues and even organs, and even incorporate intracellular enzymatic, transporter, and specific binding and non-specific absorption activities through the Michaelis-Menten equation and binding isotherms. By coupling cell-based, molecular transport simulators to other cheminformatic analysis tools, in silico screening experiments may be performed rapidly, inexpensively, reproducibly and reliably - on large number of molecules, to explore the diversity of large collections of molecules in terms of their cellular pharmacokinetic and pharmacodynamic properties.

\section{Supplementary Material}

Refer to Web version on PubMed Central for supplementary material.

\section{Acknowledgements}

This work was supported by NIH grant P20-HG003890 and RO1-GM078200. X.Z. thanks the support from the Fred Lyons Jr. Fellowship and the Schering-Plough Graduate Fellowship from the College of Pharmacy at The University of Michigan. Many thanks to Drs. Stefan Trapp and Richard W. Horobin for help with the original model ${ }^{23}$ as well as critical reading of the manuscript. Thanks also to L. Benet, G. Drusano, P.G. Schultz, G. Crippen, T. Oprea, G. Cruciani, G. L. Amidon and anonymous reviewers, for insights, suggestions, discussions and encouragement.

\section{References}

1. Artursson P, Karlsson J. Biochemical And Biophysical Research Communications 1991;175(3):880885. [PubMed: 1673839]

2. Wacher VJ, Salphati L, Benet LZ. Advanced Drug Delivery Reviews 2001;46(1-3):89-102. [PubMed: 11259835]

3. GrahamLorence S, Peterson JA. Faseb Journal 1996;10(2):206-214. [PubMed: 8641554]

4. Cao X, Yu LX, Barbaciru C, Landowski CP, Shin HC, Gibbs S, Miller HA, Amidon GL, Sun D. Mol Pharm 2005;2(4):329-340. [PubMed: 16053336]

5. Varma MV, Sateesh K, Panchagnula R. Mol Pharm 2005;2(1):12-21. [PubMed: 15804173]

6. Fantin VR, Leder P. Cancer Research 2004;64(1):329-336. [PubMed: 14729642]

7. Modica-Napolitano JS, Aprille JR. Advanced Drug Delivery Reviews 2001;49(1-2):63-70. [PubMed: 11377803]

8. Wallace KB. Pharmacology \& Toxicology 2003;93(3):105-115. [PubMed: 12969434]

9. Freddolino PL, Kalani MYS, Vaidehi N, Floriano WB, Hall SE, Trabanino RJ, Kam VWT, Goddard WA. Proceedings Of The National Academy Of Sciences Of The United States Of America 2004;101 (9):2736-2741. [PubMed: 14981238]

10. Fitzsimmons TJ, Zhao XL, Wank SA. Journal Of Biological Chemistry 2003;278(16):14313-14320. [PubMed: 12574158]

11. Kennedy T. Drug Discovery Today 1997;2(10):436-444.

12. Camenisch G, Alsenz J, van de Waterbeemd H, Folkers G. Eur J Pharm Sci 1998;6(4):317-324. [PubMed: 9795088]

13. Lloyd DG, Golfis G, Knox AJ, Fayne D, Meegan MJ, Oprea TI. Drug Discov Today 2006;11(3-4): 149-159. [PubMed: 16533713]

14. Oprea TI, Zamora I, Ungell AL. J Comb Chem 2002;4(4):258-266. [PubMed: 12099842]

15. Oprea TI. Curr Opin Chem Biol 2002;6(3):384-389. [PubMed: 12023120]

16. Balaz S, Lukacova V. JOURNAL OF MOLECULAR GRAPHICS \& MODELLING 2002;20(6): 479-490. [PubMed: 12071282]

17. Balaz S, Pirselova K, Schultz TW, Hermens J. Journal Of Theoretical Biology 1996;178(1):7-16.

18. Dvorsky R, Balaz S, Sawchuk RJ. J Theor Biol 1997;185(2):213-222. [PubMed: 9135802]

19. Amidon GL, Lennernas H, Shah VP, Crison JR. Pharm Res 1995;12(3):413-420. [PubMed: 7617530]

20. Stenberg P, Luthman K, Artursson P. Pharm Res 1999;16(2):205-212. [PubMed: 10100304] 
21. Norinder U, Osterberg T, Artursson P. Pharm Res 1997;14(12):1786-1791. [PubMed: 9453069]

22. Winiwarter S, Bonham NM, Ax F, Hallberg A, Lennernas H, Karlen A. Journal Of Medicinal Chemistry 1998;41(25):4939-4949. [PubMed: 9836611]

23. Trapp S, Horobin RW. European Biophysics Journal With Biophysics Letters 2005;34(7):959-966. [PubMed: 15895221]

24. Duvvuri M, Gong YP, Chatterji D, Krise JP. Journal Of Biological Chemistry 2004;279(31):3236732372. [PubMed: 15181006]

25. Davis S, Weiss MJ, Wong JR, Lampidis TJ, Chen LB. Journal Of Biological Chemistry 1985;260 (25):3844-3850. [PubMed: 3972850]

26. Shedden K, Brumer J, Chang YT, Rosania GR. Journal Of Chemical Information And Computer Sciences 2003;43(6):2068-2080. [PubMed: 14632459]

27. Chen VY, Khersonsky SM, Shedden K, Chang YT, Rosania GR. Mol Pharm 2004;1(6):414-425. [PubMed: 16028353]

28. Trapp S. Environmental Science And Pollution Research 2004;11(1):33-39. [PubMed: 15005138]

29. Interactive PhysProp Database Demo. available from Syracuse Research Corporation (SRC), U. S. A., (http://www.syrres.com/esc/physdemo.htm). In ed.; 'Ed.'^'Eds.' 'Vol.' p^pp.

30. Xing L, Glen RC. J Chem Inf Comput Sci 2002;42(4):796-805. [PubMed: 12132880]

31. Vrakas D, Giaginis C, Tsantili-Kakoulidou A. J Chromatogr A 2006;1116(1-2):158-164. [PubMed: 16595136]

32. Zhou C, Jin Y, Kenseth JR, Stella M, Wehmeyer KR, Heineman WR. J Pharm Sci 2005;94(3):576589. [PubMed: 15666290]

33. Ishihama Y, Nakamura M, Miwa T, Kajima T, Asakawa N. J Pharm Sci 2002;91(4):933-942. [PubMed: 11948531]

34. Balon K, Riebesehl BU, Muller BW. Pharmaceutical Research 1999;16(6):882-888. [PubMed: 10397609]

35. Wohnsland F, Faller B. J Med Chem 2001;44(6):923-930. [PubMed: 11300874]

36. McDevitt DG. Eur Heart J 1987;8:9-14. [PubMed: 2897304]

37. Avdeef A, Artursson P, Neuhoff S, Lazorova L, Grasjo J, Tavelin S. Eur J Pharm Sci 2005;24(4): 333-349. [PubMed: 15734300]

38. Martinez V, Maguregui MI, Jimenez RM, Alonso RM. J Pharm Biomed Anal 2000;23(2-3):459468. [PubMed: 10933539]

39. Castela-Papin N, Cai S, Vatier J, Keller F, Souleau CH, Farinotti R. Int J Pharm 1999;182(1):111119. [PubMed: 10332080]

40. Palm K, Luthman K, Ungell AL, Strandlund G, Artursson P. J Pharm Sci 1996;85(1):32-39. [PubMed: 8926580]

41. Yee S. Pharm Res 1997;14(6):763-766. [PubMed: 9210194]

42. Yazdanian M, Glynn SL, Wright JL, Hawi A. Pharm Res 1998;15(9):1490-1494. [PubMed: 9755906]

43. Gres MC, Julian B, Bourrie M, Meunier V, Roques C, Berger M, Boulenc X, Berger Y, Fabre G. Pharm Res 1998;15(5):726-733. [PubMed: 9619781]

44. Irvine JD, Takahashi L, Lockhart K, Cheong J, Tolan JW, Selick HE, Grove JR. J Pharm Sci 1999;88 (1):28-33. [PubMed: 9874698]

45. Hovgaard L, Brondsted H, Buur A, Bundgaard H. Pharm Res 1995;12(3):387-392. [PubMed: 7617526]

46. Pade V, Stavchansky S. Pharmaceutical Research 1997;14(9):1210-1215. [PubMed: 9327450]

47. Kasim NA, Whitehouse M, Ramachandran C, Bermejo M, Lennernas H, Hussain AS, Junginger HE, Stavchansky SA, Midha KK, Shah VP, Amidon GL. Mol Pharm 2004;1(1):85-96. [PubMed: 15832504]

48. Refsgaard HHF, Jensen BF, Brockhoff PB, Padkjaer SB, Guldbrandt M, Christensen MS. Journal Of Medicinal Chemistry 2005;48(3):805-811. [PubMed: 15689164]

49. Palm K, Luthman K, Ros J, Grasjo J, Artursson P. Journal Of Pharmacology And Experimental Therapeutics 1999;291(2):435-443. [PubMed: 10525056] 
50. Siebert GA, Hung DY, Chang P, Roberts MS. Journal Of Pharmacology And Experimental Therapeutics 2004;308(1):228-235. [PubMed: 14566005]

51. Amidon, GL. The Modern Biopharmaceutics ${ }^{\mathrm{TM}}$ Version 6 Computer Based Training Software. TSRL. Inc; 2004. 'Ed.'^'Eds.' 'Vol.' p^pp.

52. Terao T, Hisanaga E, Sai Y, Tamai I, Tsuji A. J Pharm Pharmacol 1996;48(10):1083-1089. [PubMed: 8953513]

53. Fujikawa M, Ano R, Nakao K, Shimizu R, Akamatsu M. Bioorg Med Chem 2005;13(15):4721-4732. [PubMed: 15936203]

54. Kerns EH, Di L, Petusky S, Farris M, Ley R, Jupp P. J Pharm Sci 2004;93(6):1440-1453. [PubMed: 15124203]

55. Zhu C, Jiang L, Chen TM, Hwang KK. Eur J Med Chem 2002;37(5):399-407. [PubMed: 12008054]

56. FDA. Guidance for Industry: Waiver of In Vivo Bioavailability and Bioequivalence Studies for Immediate-Release Solid Oral Dosage Forms Based on a Biopharmaceutics Classification System. 2000. ed.; 'Vol.' p.

57. Artursson P, Palm K, Luthman K. Advanced Drug Delivery Reviews 2001;46(1-3):27-43. [PubMed: 11259831]

58. Malkia A, Murtomaki L, Urtti A, Kontturi K. European Journal Of Pharmaceutical Sciences 2004;23 (1):13-47. [PubMed: 15324921]

59. Lipinski CA, Lombardo F, Dominy BW, Feeney PJ. Adv Drug Deliv Rev 2001;46(1-3):3-26. [PubMed: 11259830]

60. Flewelling RF, Hubbell WL. Biophys J 1986;49(2):541-552. [PubMed: 3955184]

61. Flewelling RF, Hubbell WL. Biophys J 1986;49(2):531-540. [PubMed: 3006814]

62. Schamberger J, Clarke RJ. Biophys J 2002;82(6):3081-3088. [PubMed: 12023231]

63. Borchard U. Clin Physiol Biochem 1990;8:28-34. [PubMed: 1982759]

64. Kirch W, Gorg KG. Eur J Drug Metab Pharmacokinet 1982;7(2):81-91. [PubMed: 6749509]

65. Mehvar R, Gross ME, Kreamer RN. J Pharm Sci 1990;79(10):881-885. [PubMed: 2280355]

66. Riddell JG, Harron DW, Shanks RG. Clin Pharmacokinet 1987;12(5):305-320. [PubMed: 2886244]

67. Neuhoff S, Ungell AL, Zamora I, Artursson P. Pharmaceutical Research 2003;20(8):1141-1148. [PubMed: 12948010]

68. Walter E, Janich S, Roessler BJ, Hilfinger JM, Amidon GL. Journal Of Pharmaceutical Sciences 1996;85(10):1070-1076. [PubMed: 8897273]

69. Egan WJ, Lauri G. Advanced Drug Delivery Reviews 2002;54(3):273-289. [PubMed: 11922948]

70. Kulkarni A, Han Y, Hopfinger AJ. Journal Of Chemical Information And Computer Sciences 2002;42 (2):331-342. [PubMed: 11911703] 
A

\section{Microvilli}

B
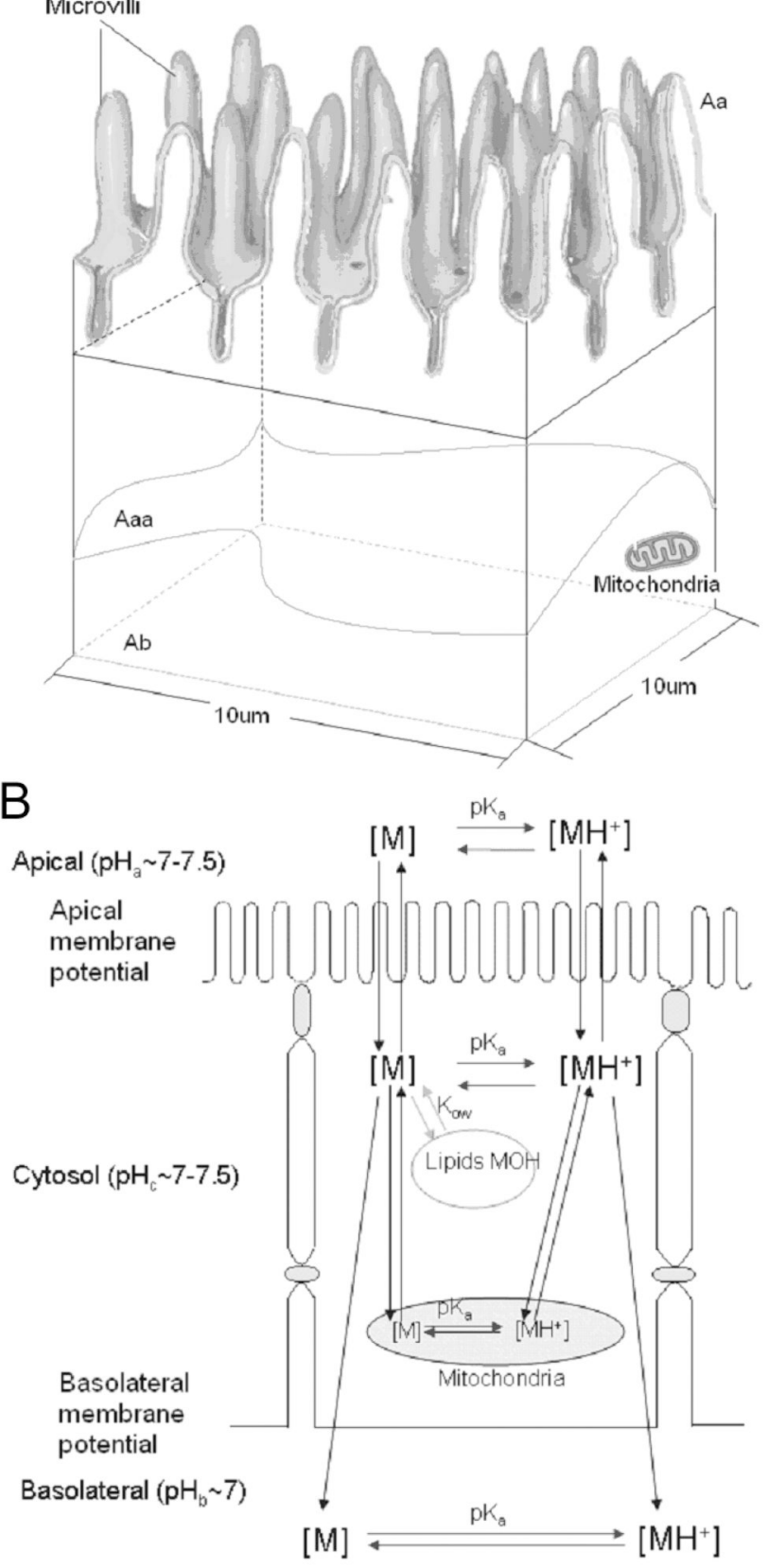

Figure 1.

Model of an intestinal epithelial cell. A) Cell morphology. B) The path of a hydrophobic weak base across an intestinal epithelial cell. The neutral form of the molecule is indicated as $[\mathrm{M}]$ and the protonated, cationic form of the molecule is indicated as $\left[\mathrm{MH}^{+}\right]$. 


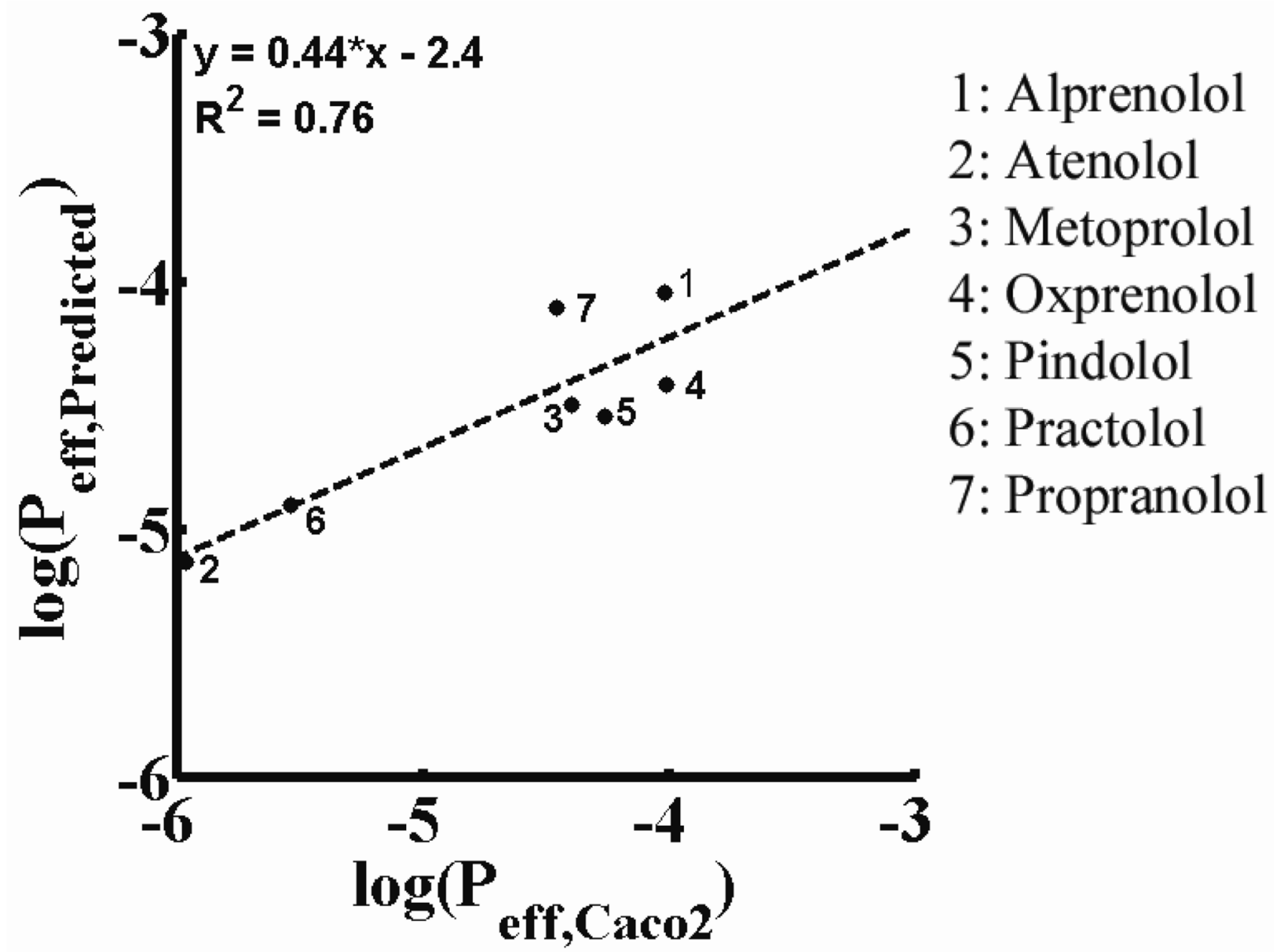

Figure 2.

Measured Caco2 permeability and predicted permeability of seven $\beta$-adrenergic receptor blockers are correlated. The $\mathrm{X}$-axis indicates the logarithm values of average measured $\mathrm{Caco} 2$ permeability $(\mathrm{cm} / \mathrm{sec})$ and the $\mathrm{Y}$-axis indicate the logarithm values of predicted permeability $(\mathrm{cm} / \mathrm{sec})$. The dotted line is the linear regression line. The linear regression equation is $y=$ $0.44 x-2.4\left(R^{2}=0.76\right)$, and the significance $\mathrm{F}$ of regression is 0.011 (confidence level is $95 \%$ ). Numbers 1 through 7 indicate alprenolol, atenolol, metoprolol, oxprenolol, pindolol, practolol, and propranolol respectively. The structures, physicochemical properties, average Caco2 permeability and predictive permeability are summarized in Table 1. 


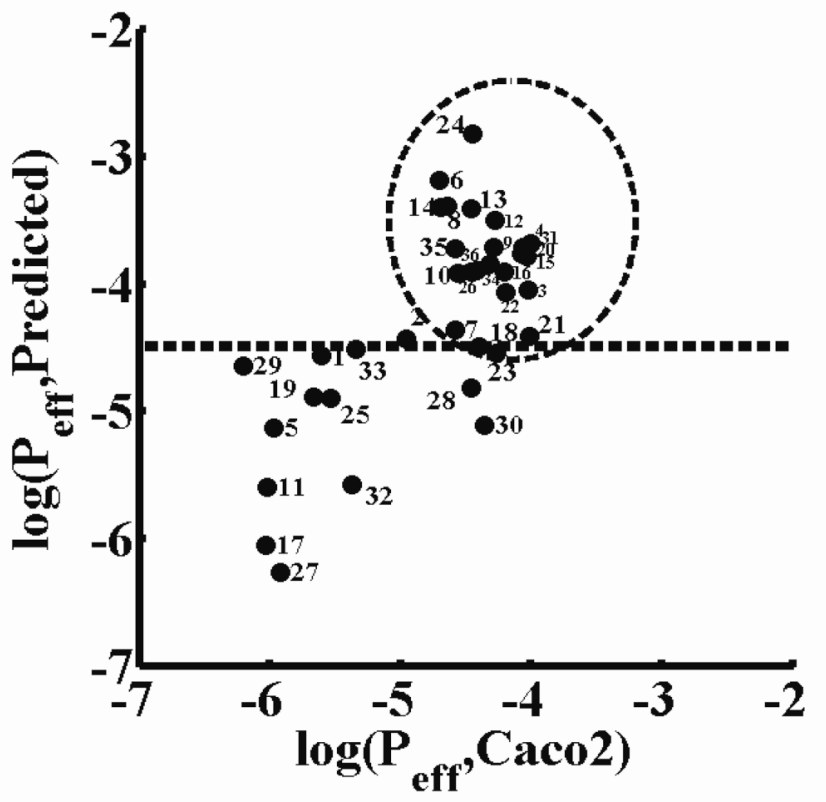

1: Acebutolol

2: Acetylsalicylic acid

3: Alprenolol

4: Antipyrine

5: Atenolol

6: Chlorpromazine

7: Clonidine

8: Desipramine

9: Diazepam

10: Diltiazem

11: Epinephrine

12: Ibuprophen

13: Imipramine

14: Indomethacin'

15: Ketoprofen

16: Lidocaine

17: Mannitol

18: Metoprolol
19: Nadolol

20: Naproxen

21: Oxprenolol

22: Phenytoin

23: Pindolol

24: Piroxicam

25: Practolol

26: Propranolol

27: Sucrose

28: Taurocholic acid

29: Terbutaline

30: Theophylline

31: Trimethoprim

32: Uracil

33: Urea

34: Valproic acid

35: Verapamil

36: Warfarin

Figure 3.

Measured Caco2 permeability and predicted permeability of thirty-seven weakly acid or basic (non-zwitterionic) drugs with a single ionizable functional group at physiological $\mathrm{pH}$. The Xaxis indicates the logarithm values of average measured Caco2 permeability $(\mathrm{cm} / \mathrm{sec})$ and the $\mathrm{Y}$-axis indicate the logarithm values of predicted permeability ( $\mathrm{cm} / \mathrm{sec})$. Metoprolol (No.18) was used as a reference drug to define predicted high vs. low permeability categories (dashed line). Compounds in the predicted high permeability category exhibit high Caco2 permeabilities (dashed circle). More detailed information and references relevant to the calculated and average $\mathrm{Caco} 2$ permeability measurements are included in the Supporting Information. 


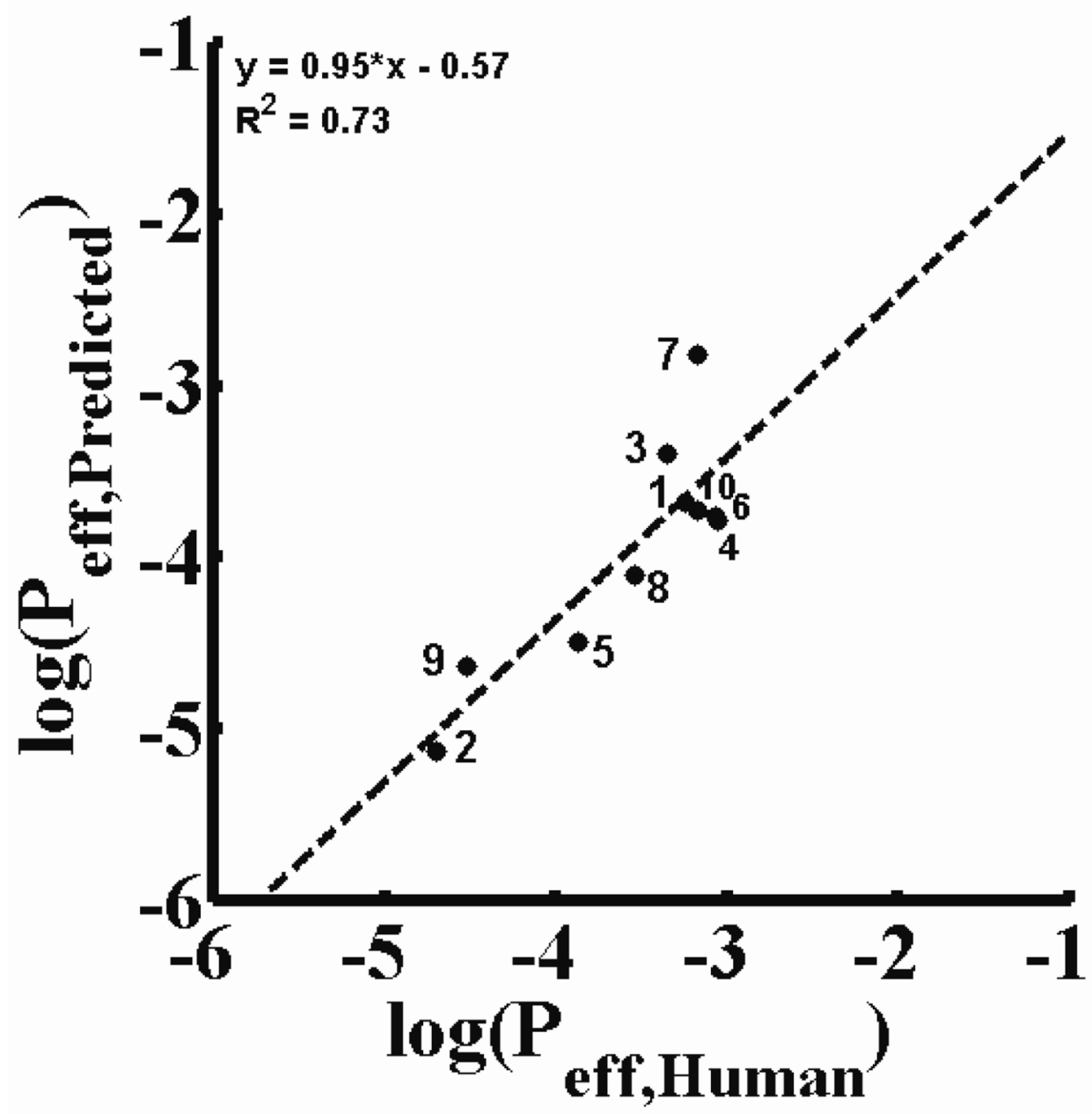

1: Antipyrine

2: Atenolol

3: Desipramine

4: Ketoprofen

5: Metoprolol

6: Naproxen

7: Piroxicam

8: Propranolol

9: Terbutaline

10: Verapamil

Figure 4.

Measured human intestinal permeability and predicted permeability are correlated. The X-axis indicates the logarithm values of measured human intestinal permeability $(\mathrm{cm} / \mathrm{sec})$ and the $\mathrm{Y}$ axis indicate the logarithm values of predicted permeability $(\mathrm{cm} / \mathrm{sec})$, for weakly acidic or basic (non-zwitterionic) drugs with a single ionizable functional group at physiological $\mathrm{pH}$. A simple linear relation was obtained and expressed by the equation: $y=0.95 x-0.57\left(R^{2}=0.73\right)$, the significance $\mathrm{F}$ of regression is 0.0016 (confidence level is $95 \%$ ). Calculated permeability and human intestinal permeability data is summarized in Table 3. 

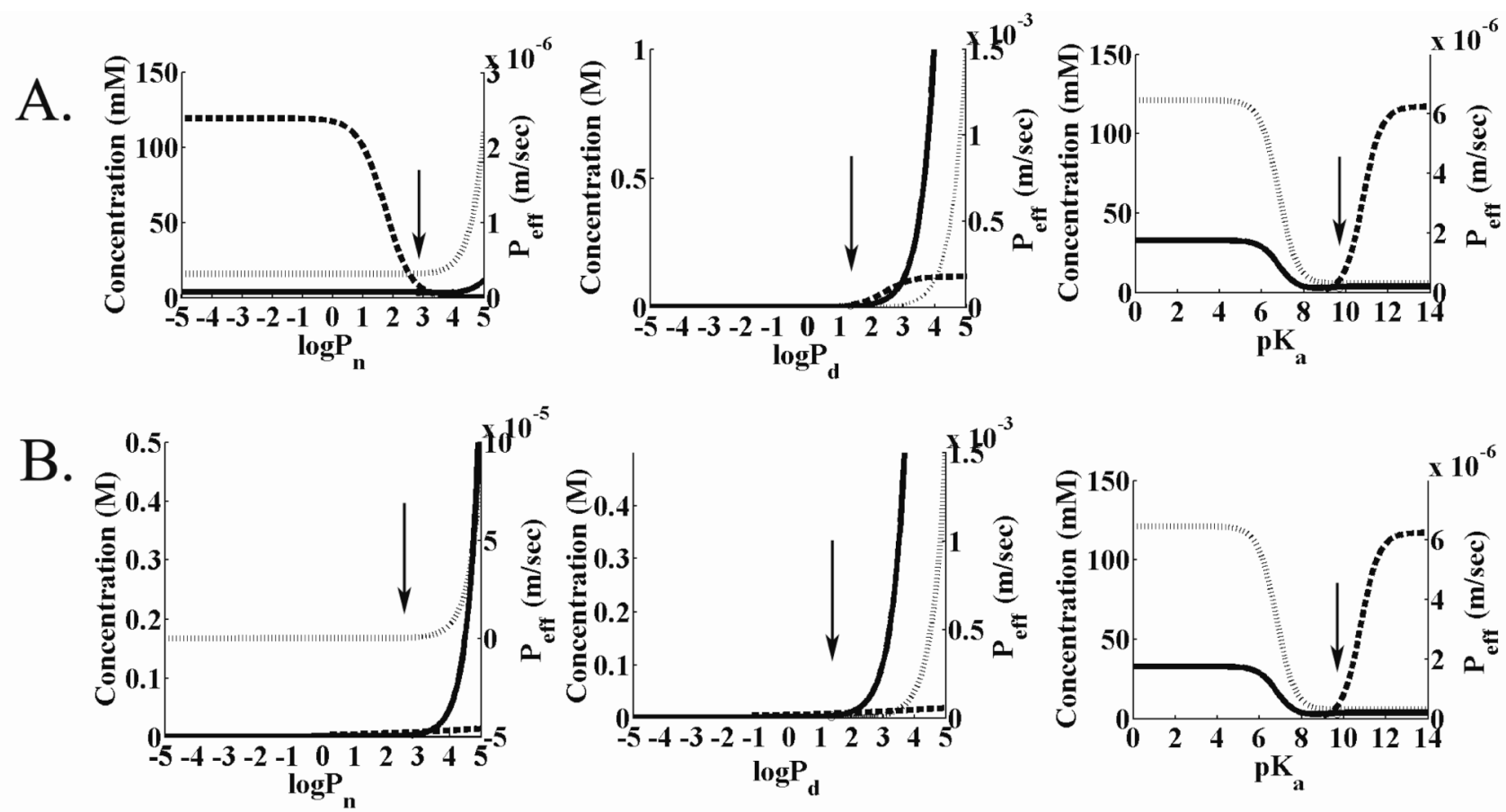

Figure 5.

Varying one physicochemical property at a time of a molecule with metoprolol-like properties (arrows) affects both the intracellular concentration (solid line = cytosolic; dark dotted line = mitochondrial) and permeability (light stippled line) at steady state. A.) Calculations based on varying $\log \mathrm{P}_{\mathrm{n}}$ and $\log \mathrm{P}_{\mathrm{d}}$ independently from each other. B.) Calculations based on varying $\log \mathrm{P}_{\mathrm{n}}$ and $\log \mathrm{P}_{\mathrm{d}}$ simultaneously, according to the linear relationship expressed as Eqn 27-Eqn 29. Arrows point to the reference liposomal $\log \mathrm{P}_{\mathrm{n}} \operatorname{lip}, \log \mathrm{P}_{\mathrm{d}}$, lip, and $\mathrm{pKa}$ of metoprolol. 
A.
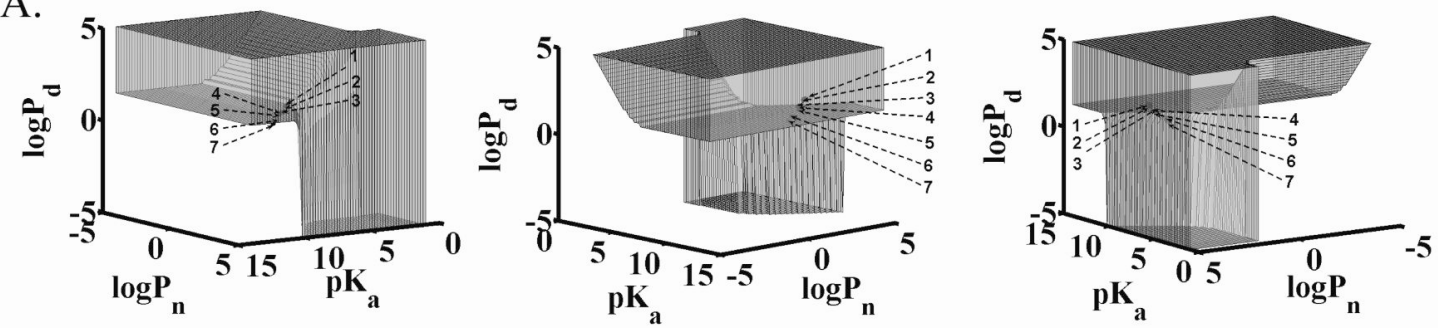

B.
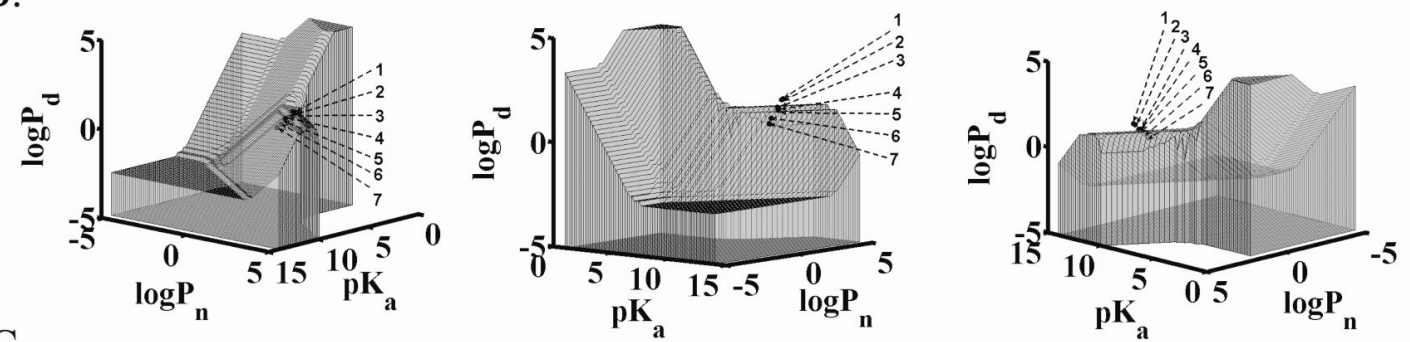

C.
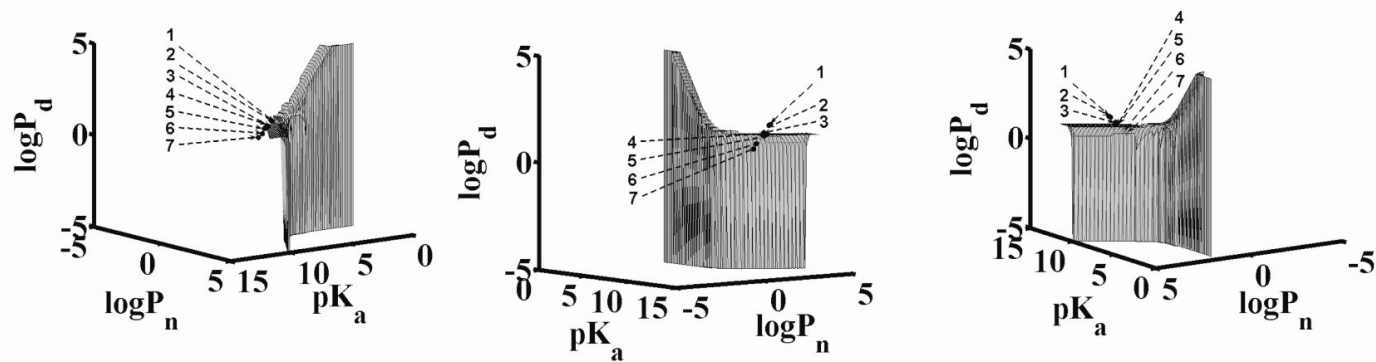

Figure 6.

The chemical space occupied by molecules with desirable A) permeability (defined as molecules with calculated $\mathrm{P}_{\text {eff }}$ equal or larger than $\mathrm{P}_{\mathrm{eff}}$ of a virtual molecule with metoprolollike properties); B) intracellular accumulation (defined as molecules with both calculated $\mathrm{C}_{\text {cyto }}$ and $\mathrm{C}_{\text {mito }}$ equal or less than that of a virtual molecule with metoprolol-like propeties); and, C) permeability and intracellular accumulation (defined as molecules with calculated $\mathrm{P}_{\text {eff }}$ equal or larger than $\mathrm{P}_{\text {eff }}$, and $\mathrm{C}_{\text {cyto }}$ and $\mathrm{C}_{\text {mito }}$ equal or less than $\mathrm{C}_{\text {cyto }}$ and $\mathrm{C}_{\text {mito }}$ than that of a virtual molecule with metoprolol-like properties. Each row is a different (rotated) view of the same, 3D physicochemical property space plot. Calculations of physicochemical property space represent simulations obtained by varying $\log \mathrm{P}_{\mathrm{n}}$ and $\log \mathrm{P}_{\mathrm{d}}$ independently from each other. Numbers 1 through 7 are alprenolol, propranolol, oxprenolol, metoprolol, pindolol, practolol, and atenolol respectively. The $\log \mathrm{P}_{\mathrm{n}}$ and $\log \mathrm{P}_{\mathrm{d}}$ values of each molecule are the liposomal values, listed in Table 1. 


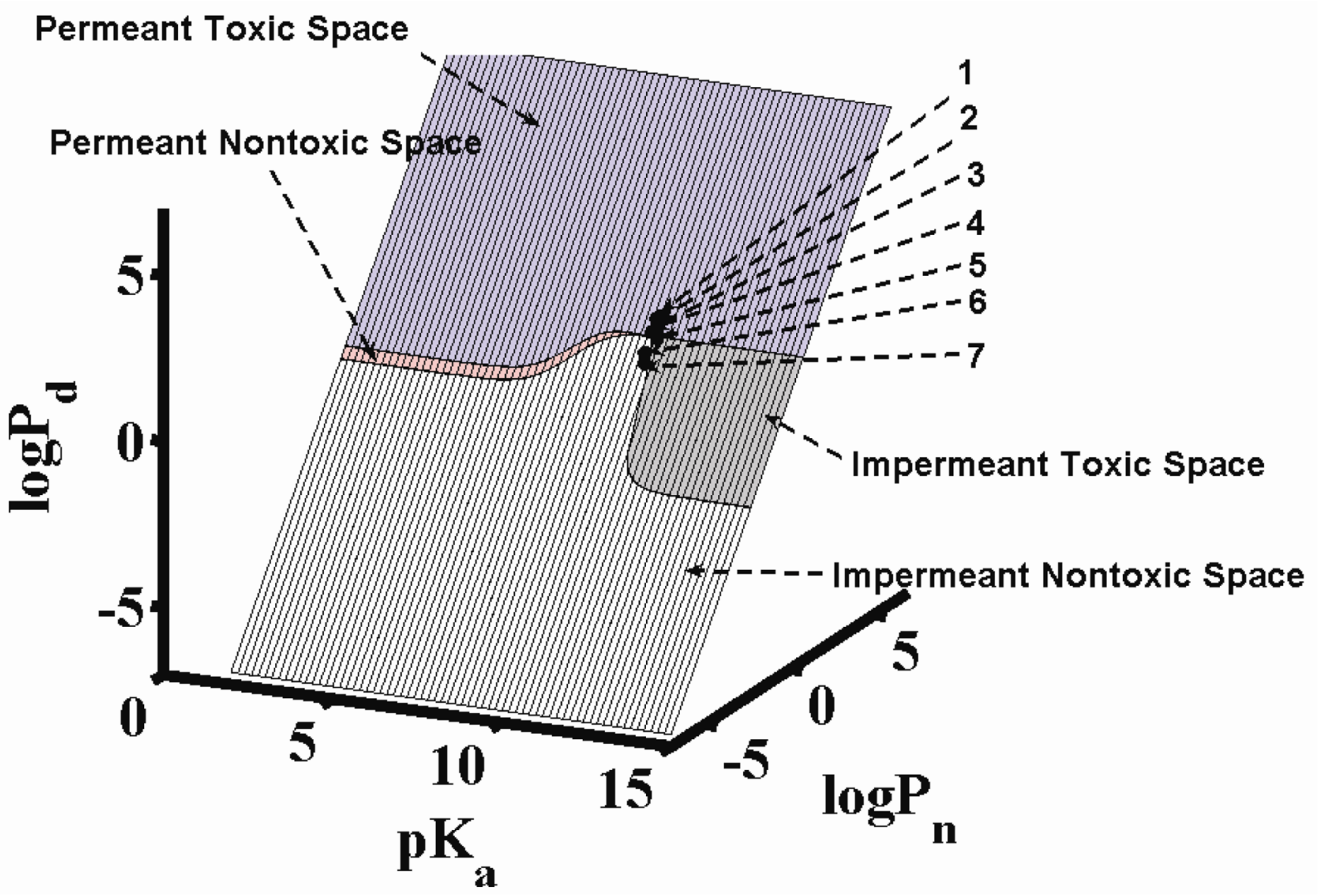

Figure 7.

The calculated physicochemical property space occupied by molecules with permeant, impermeant, toxic and nontoxic molecules, relative to a metoprolol-like reference molecule. Calculations represent results obtained by varying $\log \mathrm{P}_{\mathrm{n}}$ and $\log \mathrm{P}_{\mathrm{d}}$ simultaneously, according to the simple linear relationship expressed in Eqn 27-Eqn 29. Numbers 1 through 7 are alprenolol, propranolol, oxprenolol, metoprolol, pindolol, practolol, and atenolol respectively. The $\log \mathrm{P}_{\mathrm{n}}$ and $\log \mathrm{P}_{\mathrm{d}}$ values of each molecule are liposomal values, listed in Table 1. 


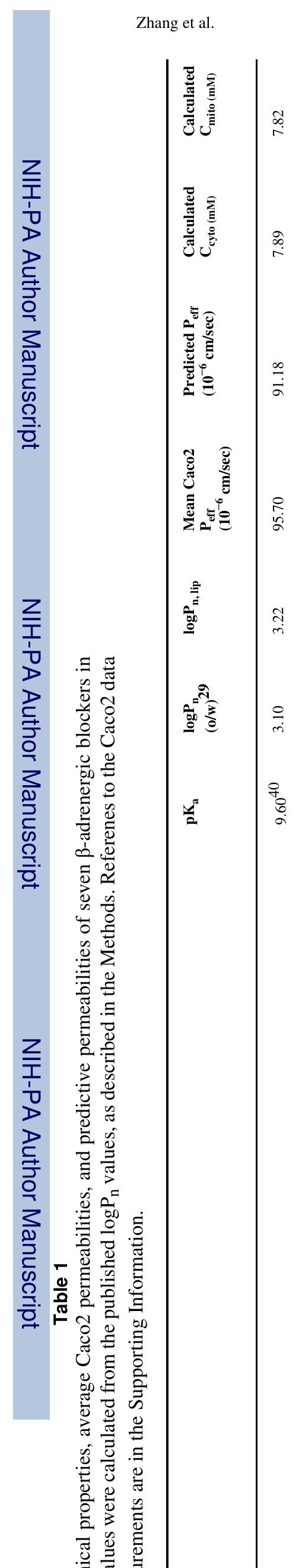

Page 24

Mol Pharm. Author manuscript; available in PMC 2009 July 15. 


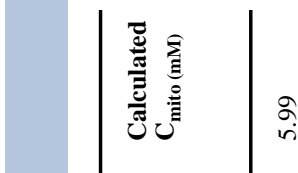

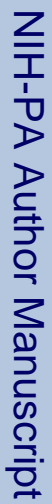

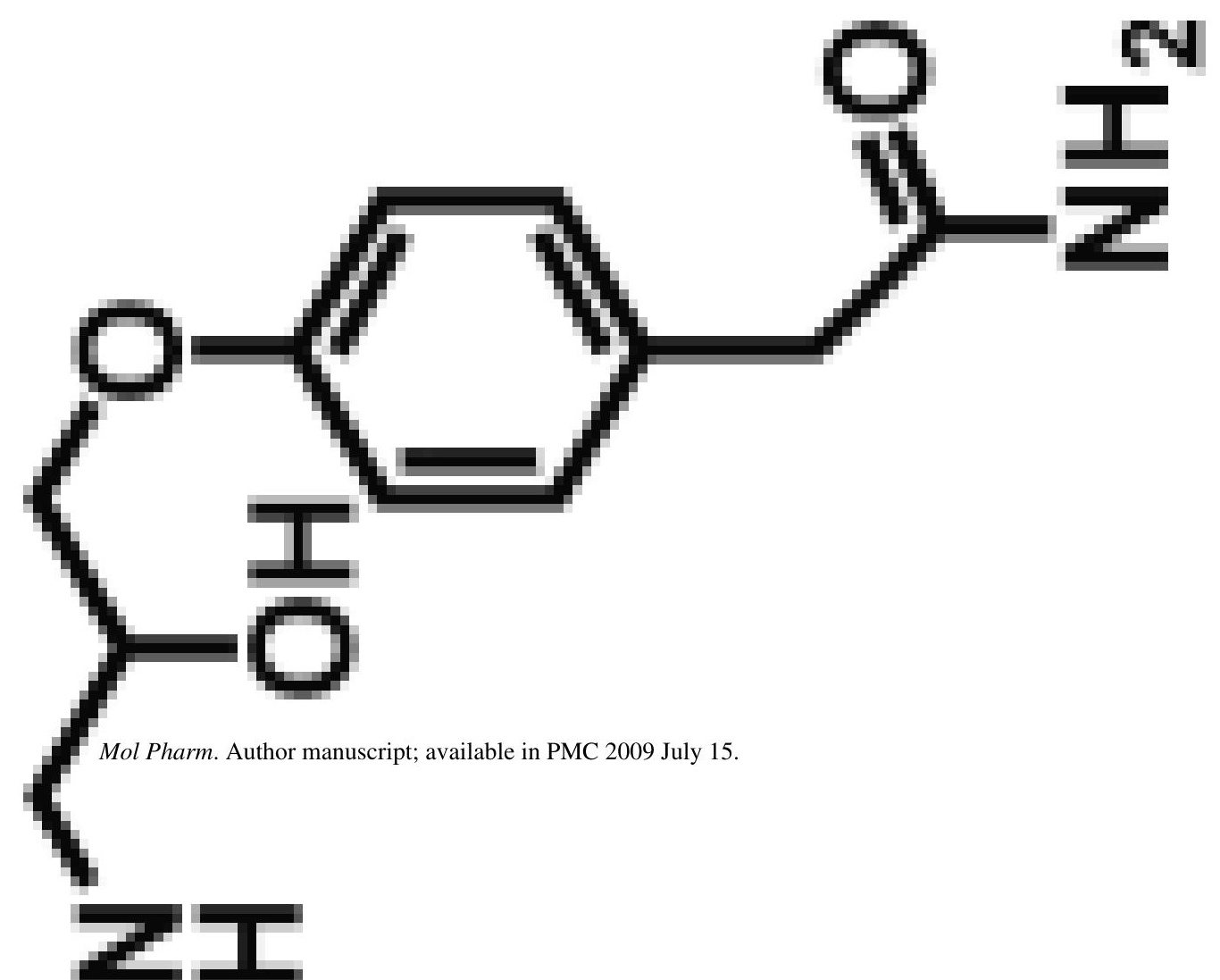




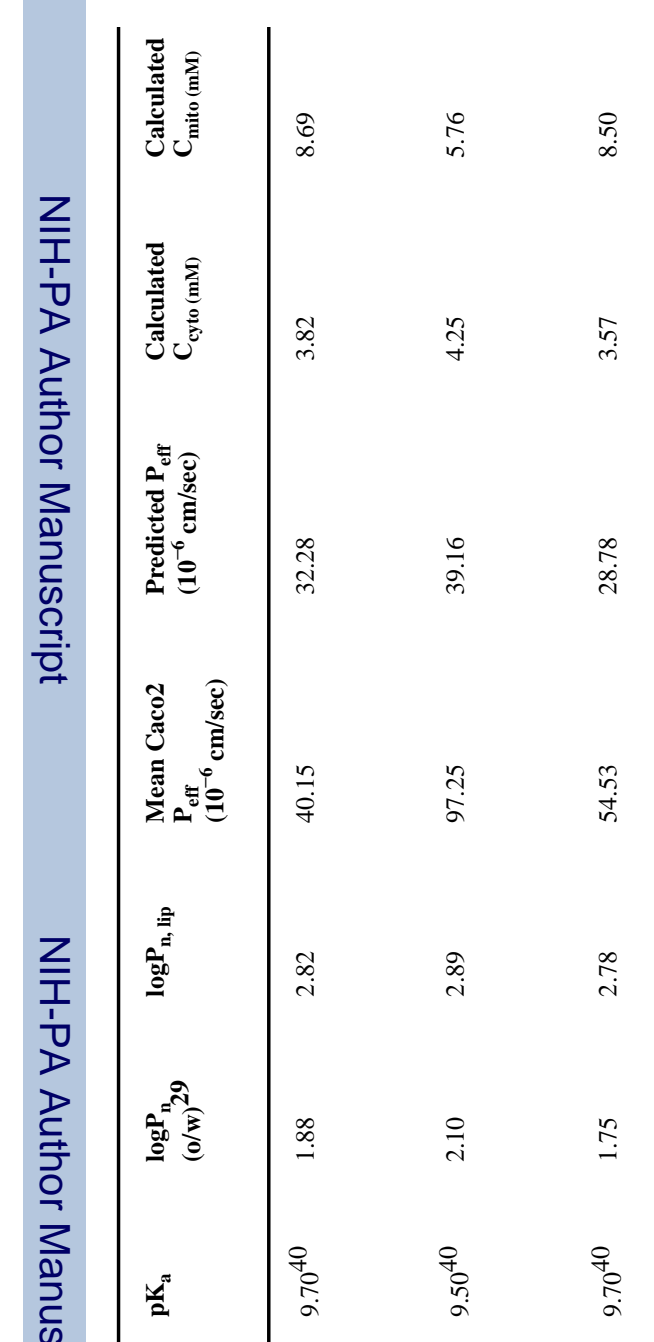




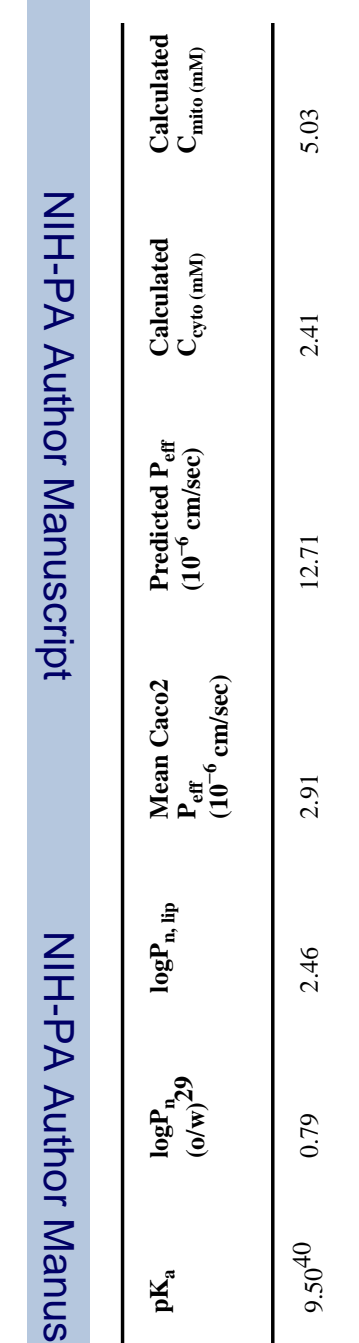




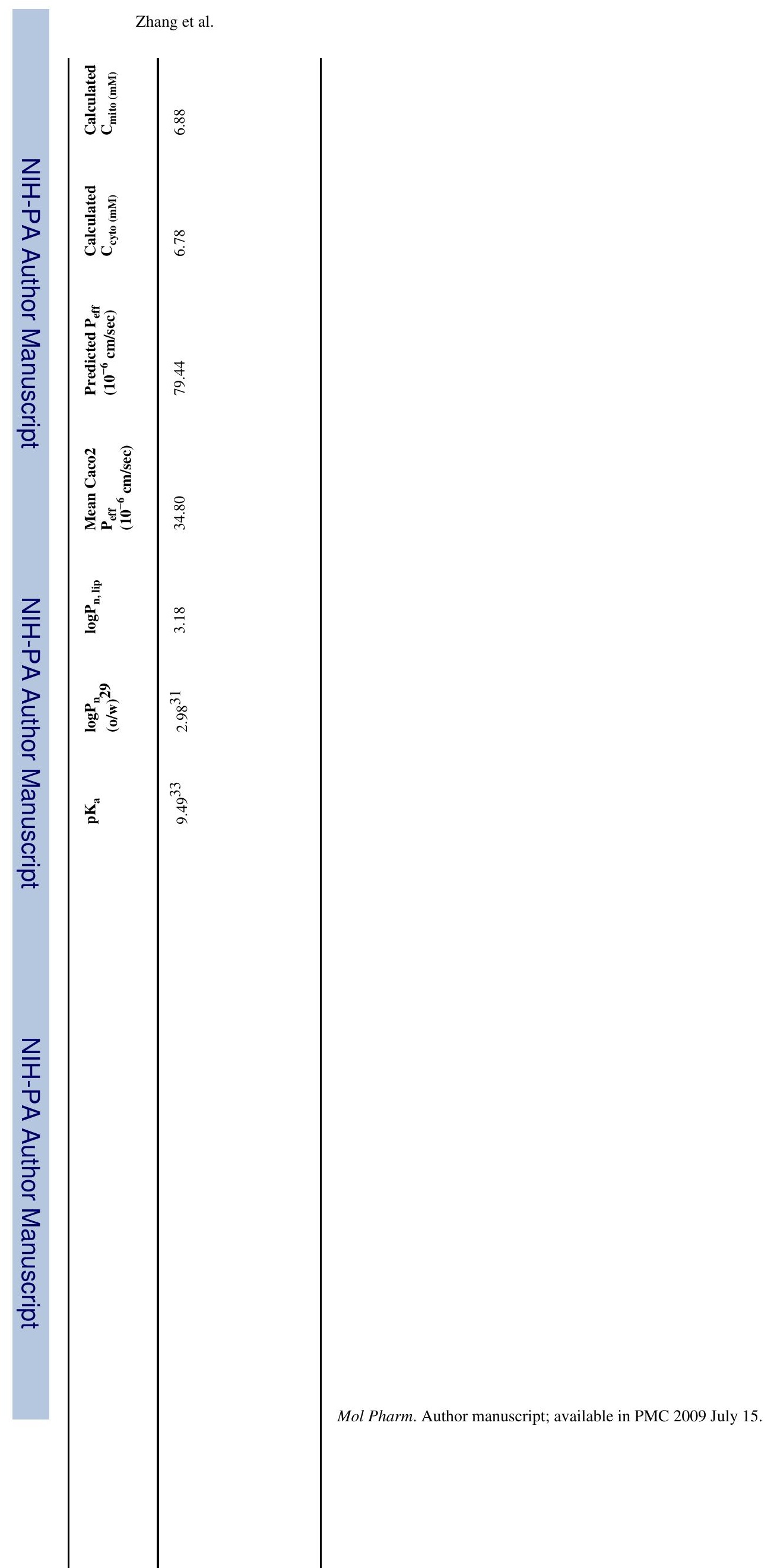

Page 28 


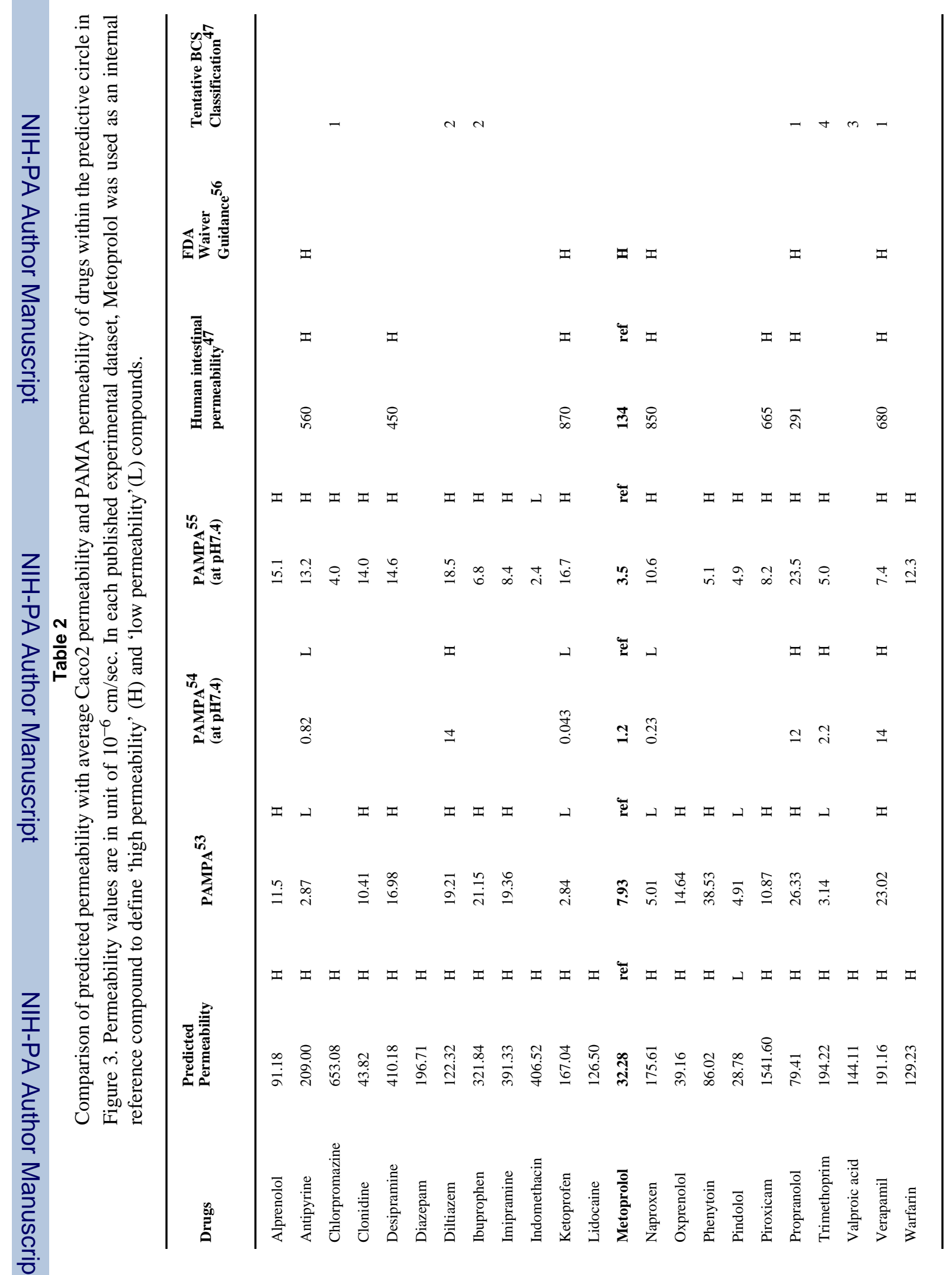


Table 3

Correlation of predicted permeability VS. human intestinal permeability. (Permeability values are in unit of $10^{-6} \mathrm{~cm} /$ sec.)

\begin{tabular}{|c|c|c|c|c|}
\hline Name & $\begin{array}{l}\text { Human } \\
\text { Permeability }\end{array}$ & $\log \left(P_{\text {eff, human }}\right)$ & $\begin{array}{l}\text { Predicted } \\
\text { Permeability }\end{array}$ & $\log \left(P_{\text {eff, predicted }}\right)$ \\
\hline Antipyrine & 560.00 & -3.25 & 209.00 & -3.68 \\
\hline Atenolol & 20.00 & -4.70 & 7.44 & -5.13 \\
\hline Desipramine & 450.00 & -3.35 & 410.18 & -3.39 \\
\hline Ketoprofen & 870.00 & -3.06 & 167.04 & -3.78 \\
\hline Metoprolol & 134.00 & -3.87 & 32.28 & -4.49 \\
\hline Naproxen & 850.00 & -3.07 & 175.61 & -3.76 \\
\hline Piroxicam & 665.00 & -3.18 & 1541.60 & -2.81 \\
\hline Propranolol & 291.00 & -3.54 & 79.41 & -4.10 \\
\hline Terbutaline & 30.00 & -4.52 & 22.96 & -4.64 \\
\hline Verapamil & 680.00 & -3.17 & 191.16 & -3.72 \\
\hline
\end{tabular}

